\title{
Roles of Neutrophils in Glioma and Brain Metastases
}

\author{
Ya-Jui Lin ${ }^{1,2,3}$, Kuo-Chen Wei ${ }^{1,4,5}$, Pin-Yuan Chen ${ }^{5,6}$, Michael Lim ${ }^{3 *}$ \\ and Tsong-Long Hwang ${ }^{2,7,8,9 *}$
}

${ }^{1}$ Department of Neurosurgery, Chang Gung Memorial Hospital, Linkou, Taiwan, ${ }^{2}$ Graduate Institute of Natural Products, College of Medicine, Chang Gung University, Taoyuan, Taiwan, ${ }^{3}$ Department of Neurosurgery, Stanford University School of Medicine, Stanford, CA, United States, ${ }^{4}$ Department of Neurosurgery, New Taipei Municipal TuCheng Hospital, Chang Gung Medical Foundation, New Taipei, Taiwan, ${ }^{5}$ School of Medicine, Chang Gung University, Taoyuan, Taiwan, ${ }^{6}$ Department of Neurosurgery, Chang Gung Memorial Hospital, Keelung, Taiwan, ${ }^{7}$ Research Center for Chinese Herbal Medicine, Research Center for Food and Cosmetic Safety, and Graduate Institute of Health Industry Technology, Chang Gung University of Science and Technology, Taoyuan, Taiwan, ${ }^{8}$ Department of Anesthesiology, Chang Gung Memorial Hospital, Taoyuan, Taiwan, ${ }^{9}$ Department of Chemical Engineering, Ming Chi University of Technology, New Taipei City, Taiwan

\section{OPEN ACCESS}

Edited by:

Susanna Mandruzzato,

University Hospital of Padua, Italy

Reviewed by:

Lisa Sevenich,

Georg Speyer Haus, Germany

Zachary J. Gerbec,

British Columbia Cancer Research

Centre, Canada

*Correspondence:

Michael Lim

mklim@stanford.edu

Tsong-Long Hwang

ht/@mail.cgu.edu.tw

Specialty section:

This article was submitted to

Cancer Immunity and Immunotherapy,

a section of the journal

Frontiers in Immunology

Received: 27 April 2021

Accepted: 19 July 2021

Published: 13 August 2021

Citation:

Lin Y-J, Wei K-C, Chen P-Y,

Lim M and Hwang T-L (2021)

Roles of Neutrophils in Glioma

and Brain Metastases.

Front. Immunol. 12:701383. doi: 10.3389/fimmu.2021.701383
Neutrophils, which are the most abundant circulating leukocytes in humans, are the first line of defense against bacterial and fungal infections. Recent studies have reported the role and importance of neutrophils in cancers. Glioma and brain metastases are the most common malignant tumors of the brain. The tumor microenvironment (TME) in the brain is complex and unique owing to the brain-blood barrier or brain-tumor barrier, which may prevent drug penetration and decrease the efficacy of immunotherapy. However, there are limited studies on the correlation between brain cancer and neutrophils. This review discusses the origin and functions of neutrophils. Additionally, the current knowledge on the correlation between neutrophil-to-lymphocyte ratio and prognosis of glioma and brain metastases has been summarized. Furthermore, the implications of tumor-associated neutrophil (TAN) phenotypes and the functions of TANs have been discussed. Finally, the potential effects of various treatments on TANs and the ability of neutrophils to function as a nanocarrier of drugs to the brain TME have been summarized. However, further studies are needed to elucidate the complex interactions between neutrophils, other immune cells, and brain tumor cells.

Keywords: neutrophils, gliobastoma, brain metastases, neutrophil extracellular traps, nanocarrier

\section{INTRODUCTION}

Paul Ehrlich coined the term neutrophils, which are also known as polymorphonuclear cells, in the late nineteenth century due to their preferential uptake of neutral $\mathrm{pH}$ dye and their inability to retain acidic or basic dyes $(1,2)$. Neutrophils, which are the most abundant circulating leukocytes in mammals, have a short life span and the neutrophil population is constantly replenished from the bone marrow (3). The first line of defense against bacterial and fungal infections is neutrophils. Additionally, neutrophils can modulate the adaptive immune response at the inflammation site through interaction with antigen-presenting cells and lymphocytes (4-6). Since the nineteenth century, inflammation has been correlated with the pathogenesis of cancer (7). Cancer-related inflammation, a hallmark of tumor biology, involves both stromal and inflammatory cells in the 
tumor microenvironment (TME) $(8,9)$. The immune privilege of the central nervous system (CNS) can be attributed to the lack of dedicated lymphatic channels in the past (10). In 2015, a novel route of lymphatic channels from the brain that runs parallel to the dural venous sinuses and travel to the deep cervical lymph nodes was identified (11).

In the 1890s, William Coley first conceived the concept of cancer immunotherapy. Ehrlich and Thomas and Burnet further developed this concept in the 1950s and 1960s, respectively (12-15). Cancer immune surveillance involves the detection and elimination of the tumor cells by the immune system $(12,15)$. Thus, cancer immunotherapies, especially immune checkpoint inhibitors (ICIs), are an emerging therapeutic modality and have revolutionized cancer management $(16,17)$. In contrast to other immune cells, such as macrophages, neutrophils were not considered to be major players in the TME. However, recent developments in genetic tools have revealed the importance of neutrophils in the TME, especially in tumor progression and tumor resistance $(2,18)$. The presence and phenotype of neutrophils in the TME determine the efficacy of both traditional and novel cancer therapies $(3,19)$.

As neutrophils play an important role in the TME, they are potential targets to enhance the efficacy of immunotherapy. However, the role of neutrophils in brain cancer biology remains unclear. In this review, we focus on the role of neutrophils in glioma and brain metastases (BMs), which are the most common malignant brain tumors. This review proposes the neutrophil-to-lymphocyte ratio (NLR) as a biomarker for brain cancer. Additionally, this review discusses the heterogeneity of tumor-associated neutrophils (TANs). Furthermore, the current therapeutic modalities using neutrophils as targets or carriers to treat glioma and BM have been summarized.

\section{ORIGIN, LIFE CYCLE, AND BIOLOGICAL FUNCTIONS OF NEUTROPHILS}

More than $10^{11}$ neutrophils are produced every day under steady-state conditions $(20,21)$. Emergency granulopoiesis is a process in which the formation of neutrophils rapidly increases in response to infection or cancer (22).

\section{Granulopoiesis}

Neutrophils are generated from lymphoid-primed multipotent progenitors (LMPPs) (23), which are derived from hematopoietic stem cells. LMPPs further differentiate into granulocyte-monocyte myeloid progenitors (24, 25). Neutrophils undergo maturation in the following steps: the formation of myeloblasts, followed by the formation of promyelocytes, myelocytes, metamyelocytes, band neutrophils, and segmented neutrophils (Figure 1) (22, 26, 27). The transitions from myeloblasts to promyelocytes, and from myelocytes to metamyelocytes are characterized by the

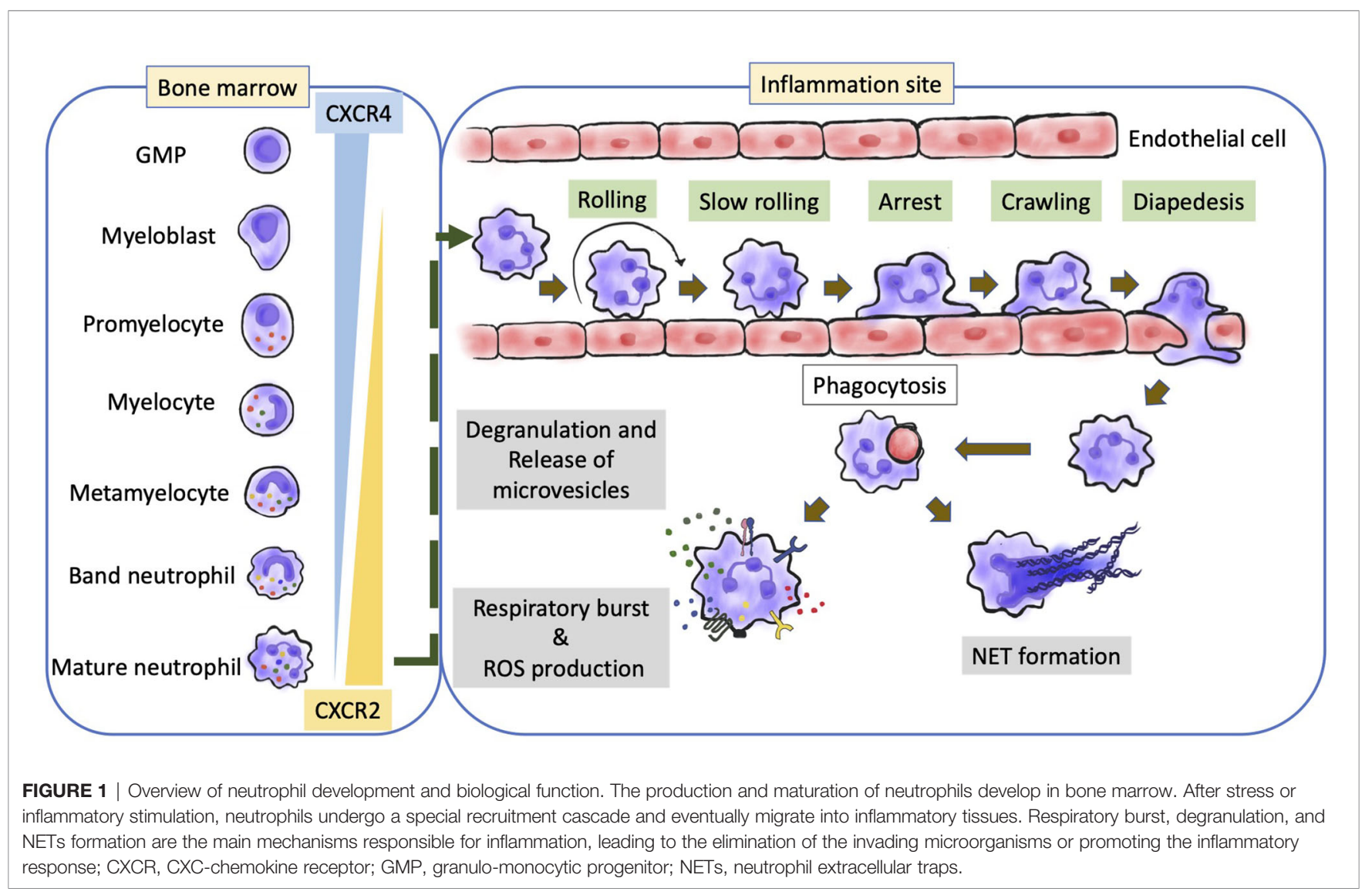


appearance of primary granules and secondary granules respectively. Meanwhile, the transition from the band neutrophils to the segmented neutrophils is characterized by the formation of tertiary granules $(21,28)$. These granules comprise various defensive factors and enzymes, such as myeloperoxidase (MPO), elastase, defensins, cathelicidins, and matrix metalloproteinases (MMPs), which protect against opportunistic infections and mediate the alleviation of inflammation $(28,29)$.

Granulocyte colony-stimulating factor (G-CSF), which is the master regulator of neutrophil generation and differentiation (30-32), can induce the proliferation and differentiation of myeloid progenitors. The expression of G-CSF receptor (G-CSFR) is detected in the myeloid lineage from the early stem and progenitor cells to fully differentiated neutrophils (33, 34). G-CSFR-signal transducer and activator of transcription 3 (STAT3) signaling regulates neutrophil formation (35). Other molecules, such as granulocytemacrophage colony-stimulating factor (GM-CSF), interleukin 6 (IL-6), and KIT ligand (also known as KITLG) are reported to be involved in granulopoiesis (36-38). For example, these cytokines are upregulated in several animal models of cancer, which results in enhanced granulopoiesis and neutrophilia (39-45).

\section{Neutrophil Retention and Release From the Bone Marrow}

In contrast to other immune cells, neutrophils are released from the bone marrow as terminally differentiated mature cells. Under homeostatic conditions, approximately $1 \%-2 \%$ of all neutrophils are mature neutrophils that circulate throughout the body (46). The immature cells are retained in the bone marrow due to the interaction between $\mathrm{C}-\mathrm{X}-\mathrm{C}$ chemokine receptor 4 (CXCR4) and CXCR2 (Figure 1). Osteoblasts and other bone marrow stromal cells constitutively express CXCL12 and tether CXCR4+ neutrophils (immature) in the bone marrow. Meanwhile, mature neutrophils exhibiting CXCR2 expression are released into the circulation through the interaction with CXCL1 and CXCL2 secreted by the endothelial cells and megakaryocytes (47-52). Several adhesion molecules, such as integrin subunit $\alpha 4$ (ITG $\alpha 4$ ), vascular cell adhesion molecule 1 (VCAM1), and some proteases also play a critical role in neutrophil retention (52-55). $\mathrm{G}-\mathrm{CSF}$ is reported to be a disruptor of neutrophil retention (56).

The molecules that regulate neutrophil release into the circulation are upregulated in tumors. These molecules override the neutrophil retention signals in the bone marrow to facilitate neutrophil egress and consequently increase neutrophil counts (39$42,57)$. In addition to cytokines derived from tumor cells (41, 42, 57), stromal and immune cells can upregulate the expression of these molecules in tumor-bearing mice. The aberrant production of cytokines by the tumors or stromal cells can cause an imbalance in neutrophil retention and release from the bone marrow.

\section{Biological Functions}

Neutrophils regulate immunity and inflammation by recognizing and responding to microbial and inflammatory stimuli $(58,59)$.
Phagocytosis and enzymatic processes (Figure 1), including the generation of reactive oxygen species (ROS) through the NADPH oxidase 2 (NOX2) and the release of granule-derived MPO, hydrolytic enzymes (such as elastase, lysozyme, and MMPs), and other antimicrobial proteins/peptides (such as lactoferrin and defensins) can eliminate the invading microorganisms after pathogen recognition $(60,61)$. Neutrophil granule-derived molecules can directly kill microorganisms, mediate positive feedback loops in neutrophils, or attract and activate monocytes $(62,63)$. Classical effector responses interact with each other at several levels, including the primary release of granules into the phagosome, processing of NOX2-derived superoxide and $\mathrm{H}_{2} \mathrm{O}_{2}$ by granule-derived MPO, or NOX2-mediated activation of granule proteins $(60-62,64)$. Neutrophils also release their DNA into the extracellular space to form neutrophil extracellular traps (NETs), a complex of DNA and neutrophilderived antimicrobial molecules (Figure 1) (65). In addition to trapping and killing bacteria (65), NETs are involved in various inflammatory diseases (66). NET formation (also called 'NETosis') is dependent on MPO, neutrophil elastase, peptidylarginine deiminase 4 (PAD4), and gasdermin $\mathrm{D}$, which are potential therapeutic targets for NET-mediated pathologies (67-69). The genetic deficiency of NET-degrading DNases results in the development of NET-mediated vascular occlusion (70). However, previous studies have reported controversial findings on NETs generation and function.

Neutrophils can release various chemokines, cytokines, and lipid mediators through modulation of gene expression although they exhibit limited transcriptional activity (71-73). Therefore, neutrophils are involved in regulating the immune response and the interaction of various immune and non-immune cells (74-76). However, the functional relevance of these neutrophil-derived mediators is not completely understood. Neutrophils also release extracellular vesicles that exhibit antimicrobial functions (77), mediate the effects of neutrophil-derived LTB4, and contribute to the pathogenesis of inflammation and cancer (78-80).

\section{CURRENT THERAPEUTIC STRATEGIES FOR GLIOMA AND BMs}

Brain tumors are a mixed group of primary and metastatic neoplasms that exhibit varying degrees of malignancy. Although malignant lesions are uncommon, their incidence has increased rapidly in highly developed and industrialized countries (81). Malignant brain tumors directly affect neurological function, psychological health, and quality of life (82). In the last few decades, advances in diagnostic methods, including the development of computed tomography in the mid1970 s and magnetic resonance imaging (MRI) in the mid-1980s, have revealed an increased incidence of brain tumors $(83,84)$.

Glioma is the most prevalent type of primary malignant brain tumor. Glioblastoma (GBM) is the worst grade of glioma with a median overall survival of 14 to 17 months and a five-year 
survival rate of only $5.6 \%$ despite of the traditional triad of surgical excision, radiotherapy, and chemotherapy (85-88). Recently, tumor-treating fields, which involve the use of lowintensity alternating electric fields to interfere with cell division and organelle assembly, have been demonstrated to extend the OS of patients with glioma to 20.9 months (89). Besides, several studies have focused on immunotherapy as an effective treatment paradigm $(90,91)$. The results of phase I and II clinical trials on cancer vaccines were encouraging. The synergistic effects of antitumor vaccines and standard therapy have been previously demonstrated (92-96). Immunotherapy is believed to be a promising approach for enhancing the efficacy of the current chemoradiation regimen. However, phase III clinical studies have revealed the poor efficacy of ICIs and vaccine therapy for GBM. Nivolumab (monoclonal antibody to PD-1) of checkMate 143 (NCT02017717) (97) and Rindopepimut (EGFRvIII specific peptide and KLH conjugate) of ACT IV (NCT01480479) (98) both terminated early because no significant survival benefit. There are several obstacles to the success of GBM immunotherapy, such as the heterogeneity and low mutation burden of the tumors and local/systemic immunosuppression induced by GBM (99-103).

BMs, which occur in $10 \%-40 \%$ of patients with cancer, are the most common malignant brain tumors in adults $(104,105)$. The increased surveillance and improved control of primary cancer resulting in prolonged survival have increased the incidence of BMs (106). The most common primary sites of BMs are lung and breast carcinomas and melanoma (107). The management of BMs has been revolutionized by improved brain imaging and management of systemic diseases, distribution of stereotactic irradiation, and the development of less invasive surgical techniques that enable the removal of BMs even from eloquent brain areas with minimal morbidity (108). Although whole-brain radiation therapy (WBRT), stereotactic radiosurgery (SRS), and systemic therapies have improved the treatment outcomes, surgical resection is the major therapeutic strategy for large BMs. The indications for resection include a symptomatic mass, a mass with edema requiring high-dose steroids, a mass with a size more than $3 \mathrm{~cm}$, and a mass with an unknown primary cancer (108). In addition, recent advances in immunotherapy have increased the therapeutic options for patients with metastatic melanoma. Ipilimumab (monoclonal antibody to CTLA-4) and nivolumab can stimulate $\mathrm{T}$ cellmediated anti-tumor immune response. Previous studies have reported that ipilimumab treatment achieves CNS disease control in $24 \%$ of patients with melanoma exhibiting asymptomatic $\mathrm{BM}$ and $10 \%$ of patients with the symptomatic disease (109). Additionally, dual immune checkpoint blockade of ipilimumab and niolumab has achieved higher intracranial responses (110). However, the efficacy of other ICIs for BMs has not been examined.

The understanding of the interaction of immune cells in the brain TME can aid in the development of effective immunotherapy strategies. Neutrophils, which are abundant in the circulation, are a potential therapeutic target for BMs as they have critical roles in immunity and inflammation. Therefore, many recent researches focused on the analyses of brain immune TME landscape via flow cytometry, RNA sequencing, protein arrays, culture arrays, and spatial tissue characteristics in glioma and BMs $(111,112)$. Disease-specific immune cells enriched with pronounced differences in tissue-resident microglia, infiltrating monocytederived macrophages, neutrophils, and $\mathrm{T}$ cells between gliomas and BMs. Abundance of TAMs infiltrated in gliomas, whereas $\mathrm{T}$ cells were much fewer. However, lymphocytes and neutrophils accumulated obviously in BMs. This implies that tumors indeed shape their TME while growing within the brain. It is different from cancers that metastasize from extracranial sites. In addition, there were additional differences for BMs originated from distinct primary tumors. For example, abundance of CD4+ and CD8+ $\mathrm{T}$ cells represented the major immune compartment in melanoma BMs, whereas it showed the highest neutrophil infiltration in breast BMs. Therefore, defining the specific immunological signature of brain tumors can facilitate the rational design of targeted immunotherapy strategies.

\section{NLR AS A BIOMARKER}

The local inflammatory process in the TME and systemic inflammation play important roles in cancer development and progression (113-115). The hallmarks of cancer-related inflammation include the presence of inflammatory cells and inflammatory mediators (for example, chemokines, cytokines and prostaglandins) in tumor tissues similar to that seen in chronic inflammatory responses (8). The upregulated levels of Creactive protein, hypoalbuminemia, some cytokines, and leukocytes and their subtypes in the blood can be quantified to determine systemic inflammation $(116,117)$.

Inflammatory cytokines and chemokines, which can be produced by both tumor and stromal cells, contribute to the progression of malignancy (7). The increased NLR has been associated with increased peritumoral infiltration of macrophages and upregulation of several cytokines, such as IL-6, IL-7, IL-8, IL-9, IL-12, IL-17, and interferon- $\gamma$ (IFN $\gamma$ ) $(118,119)$. Neutrophils and macrophages are reported to secrete tumor growth-promoting factors, including vascular endothelial growth factor $(120,121)$, hepatocyte growth factor (122), IL-6 (123), IL-8 (124), MMPs (125), and elastases (126), which promote the development of pro-tumor TME. Nevertheless, IL-12 and IFN $\gamma$ are reported to enhance antitumor effect. IL-12 can be used as combinatorial immunotherapy and effective in preclinical glioblastoma model (127). On the other hand, cancer-related inflammation, like smouldering inflammation, in the TME has many pro-tumor effects. It exacerbates progression of malignant cells, promotes angiogenesis and metastasis, suppresses adaptive immune responses, and alters responses to hormones and chemotherapeutic agents (8). Therefore, the cons and pros of inflammation in cancer are still needed to be elucidated in the future.

Thus, biochemical markers of inflammation in patients with various cancers have been incorporated into prognostic scores (128). Neutrophilia, an inflammatory response, inhibits the 
immune system by suppressing the cytolytic activity of immune cells, such as cytotoxic T cells and natural killer (NK) cells (129, 130). Several studies have reported the critical roles of tumorinfiltrating lymphocytes (TILs) in cancer. The upregulation of TILs has been associated with improved treatment response and prognosis (131-133). Therefore, an elevated NLR in peripheral blood was recognized as a poor prognostic indicator recently (134). The mechanisms underlying the correlation between high NLR and poor prognosis in patients with cancer have not been elucidated.

Recent studies have developed sensitive and accurate biomarkers for cancer. The changes in the blood NLR can be used to determine the optimal therapy for patients with advanced-stage cancer $(135,136)$. The prognostic value of NLR in early-stage cancer is lower than that in patients with advanced-stage cancer. However, NLR can aid in the evaluation of the early effects of systemic therapy (137-140). Some small-scale studies have reported that chemotherapy improved the clinical outcomes of patients with cancer through the alleviation of dysregulated NLR $(135,136)$.

Most patients with glioma exhibit neutrophilia (141) due to the increased production of G-CSF by tumor cells to promote growth $(142,143)$. G-CSF shifts bone marrow hematopoiesis toward the myeloid lineage and away from the lymphocyte lineage. This leads to a high NLR in patients with glioma. Several studies have demonstrated that the NLR of more than 4 is associated with poor prognosis when examined before treatment $(144,145)$, after the second surgery (146), and after TMZ and RT therapies (147). NLR of less than 4 is associated with improved prognosis in GBM with wild-type IDH1 (148). The baseline neutrophil count in the blood can also predict bevacizumab efficacy in patients with GBM (149). The upregulated surface expression of CD11b, a marker of neutrophil activation, can be used as an early predictor of tumor progression in patients with GBM (150). Arginase I produced by circulating neutrophils promotes tumor growth and induces immunosuppression (151).

The OS of patients with BMs is poor (152). Therefore, there is a need to develop multidisciplinary and individualized treatment approaches for BMs. Prognostic models with recursive partitioning analysis and graded prognostic assessment that incorporate multiple patient factors have been established to predict the treatment outcomes $(153,154)$. Although patients exhibit prolonged survival and undergo novel therapies, including targeted and immune therapy with SRS, novel factors must be incorporated into the predictive system to examine the survival benefits of novel therapies. Recently, NLR has been identified as one of the markers for predicting the outcomes of novel therapies $(9,155)$. The inflammatory cells are reported to cross into the brain (11). Hence, the association between NLR and OS in patients with $\mathrm{BM}$ was investigated. Several studies have investigated the optimal dichotomous cutoff values of NLR in various BMs. NLR values of more than 5, 3.3, and 6 are correlated with poor outcomes of postresection, pre-SRS, post-SRS, respectively (156-158). There were no common optimal dichotomous cutoff values for NLR in all studies. The optimal NLR to predict OS in various malignancies ranged from 2.18 to $7.5(144,147,159-161)$. The increased NLR value is reported to be correlated with a high risk of local recurrence. Patients with elevated NLR are likely to exhibit neuronal death (157). Prospective validation must be performed to validate the simple and systemic marker NLR for determining if aggressive treatment is needed following initial treatment. Further studies are needed to examine the interaction between BMs and immunological environments.

Thus, NLR has been proposed as a surrogate marker for the prognosis of various cancers as lymphocyte and neutrophil counts can be easily determined based on the complete blood count. However, acute conditions, such as bacterial or viral infections or drug treatments may overlap chronic ongoing inflammation and affect the neutrophil and lymphocyte counts. Hypertension, diabetes mellitus, metabolic syndrome, left ventricular dysfunction and hypertrophy, acute coronary syndromes, cardiovascular diseases $(162,163)$, abnormal thyroid function tests, renal or hepatic dysfunction, previous history of infection ( $<3$ months), inflammatory diseases (164), and some medications (e.g. steroids) can potentially affect the measurement of NLR. Therefore, NLR must be carefully validated.

\section{TAN HETEROGENEITY AND NETS}

The complex roles of neutrophils in both tumor growth and metastasis have been reported. The role of neutrophils in cancer is dependent on various factors and may result in a pro-tumoral or an antitumoral effect (2). TANs in the TME and the functions of neutrophils, including circulating and bone marrow neutrophils and neutrophil lineage cells, determine their role in cancer. TANs are polarized to anti-tumor (N1) or pro-tumor (N2) phenotypes (Figure 2) (165). Since 2015, the functional plasticity of TANs and their ability to undergo alternative activation upon exposure to various cues in the TME have been demonstrated $(166,167)$. For example, the presence of transforming growth factor- $\beta$ (TGF $\beta$ ) promotes a pro-tumor phenotype (N2 TANs), whereas the presence of IFN $\beta$ or the inhibition of TGF $\beta$ signaling promotes the anti-tumor phenotype of TANs (N1 TANs) (165, 168). The binary N1/N2 phenotypes maybe an oversimple classification system to describe neutrophil polarization, as well as the M1/M2 phenotypes for TAMs (169-171). Neutrophil polarization may involve a spectrum of activation states. Multiple heterogeneous neutrophil subsets have been observed in the circulation of both tumor-bearing mouse models and patients with cancer. The following three distinct neutrophil populations have been identified in the circulation of both patients with cancer and mouse models: mature high-density neutrophils (HDNs), mature low-density neutrophils (LDNs), and immature LDNs (172-175). Mature HDNs exhibit an antitumor N1-like phenotype. However, mature LDNs, which are not cytotoxic, exhibited impaired functions and immunosuppressive properties (172-174).

The dual and opposite functions of neutrophils in tumor immunity may vary during the progression of cancer (173). Neutrophils can influence tumor development by modulating 
A

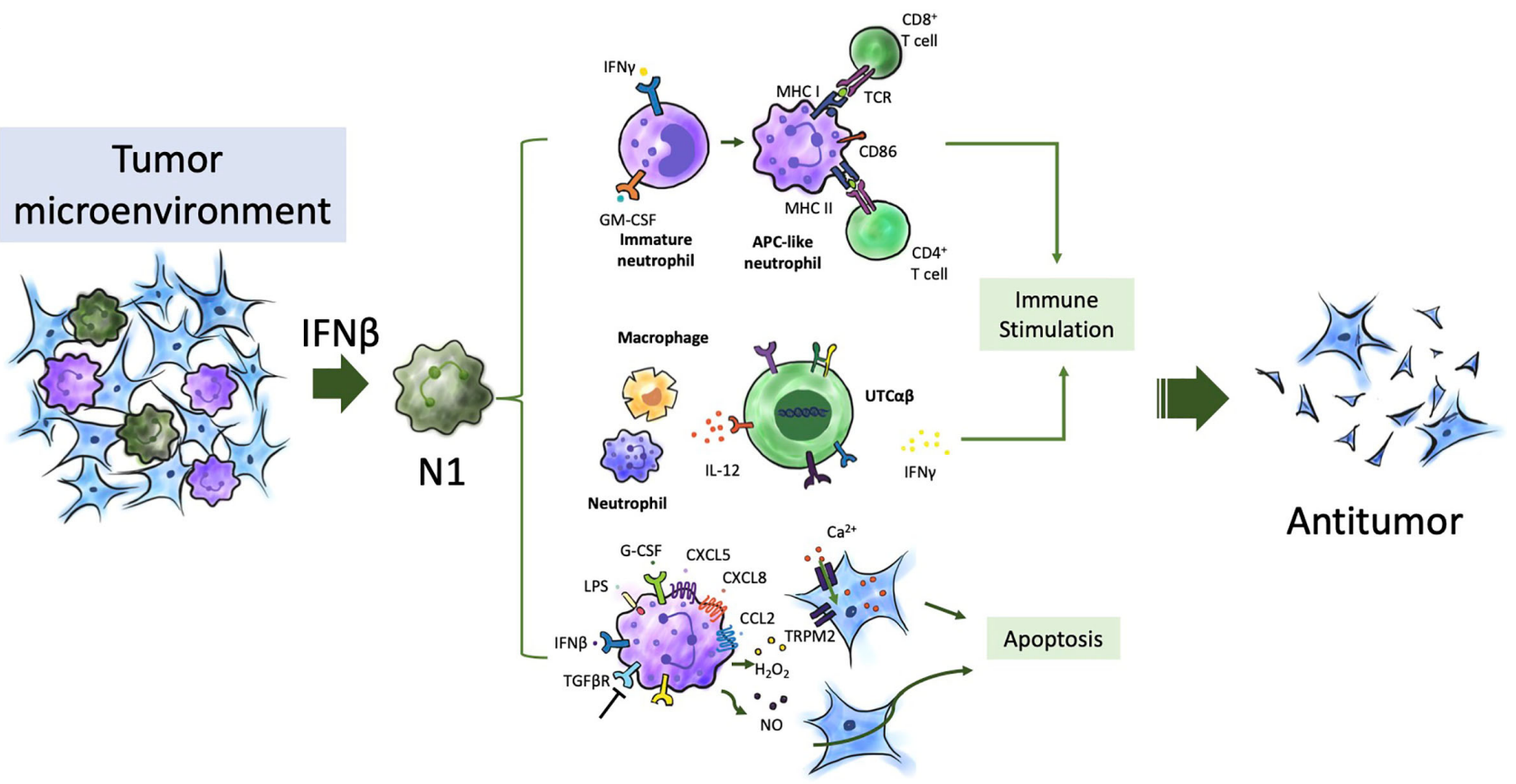

B
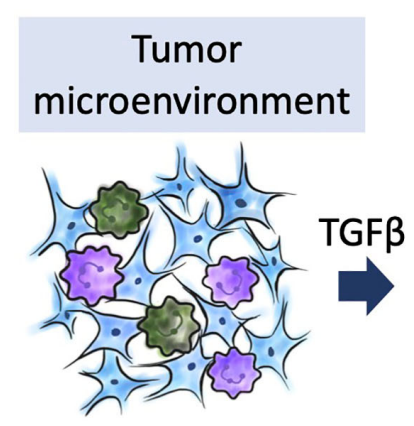
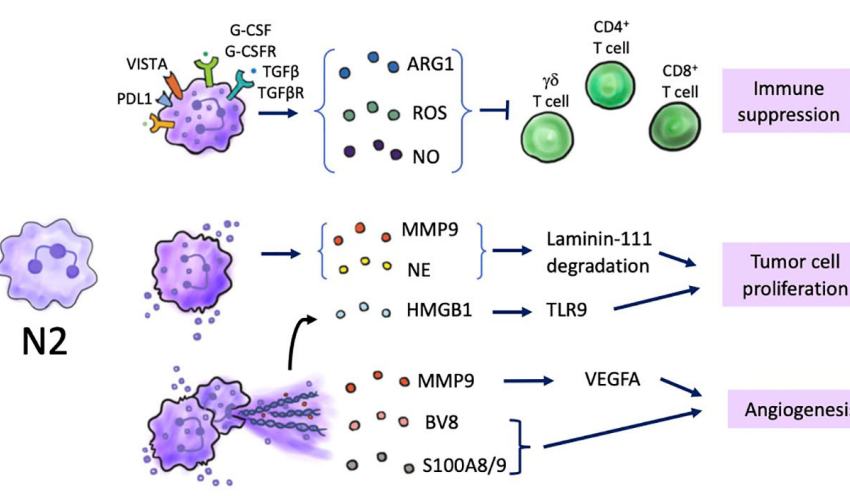

Tumor cell proliferation

Angiogenesis

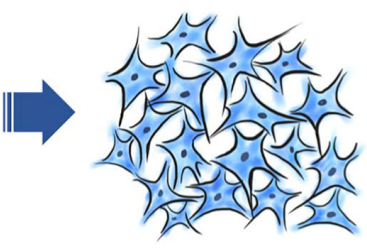

Pro-tumor

FIGURE 2 | Neutrophils in tumor microenvironment. TANs participate in different stages of tumorigenesis, and are polarized into N2 (pro-tumor) in the presence of TGF- $\beta$, and polarized into N1 (antitumor) in the presence of IFN- $\beta$ in the TME. (A) APC-like neutrophils from immature neutrophils with presence of GM-CSF and IFNy express MHC I/II and the co-stimulatory molecules CD86, 4-1BB ligand (4-1BBL) and OX40 ligand (OX40L), which enhance $T$ cell immunity. $U_{T} C_{\alpha \beta}$, essential for effective antitumor immunity, can be polarized to a type 1 immune response and IFN $\gamma$ production through IL-12 production from macrophage which was amplified by neutrophils. Different stimuli (G-CSF) and chemokines of CXCL5/8, and CCL2, LPS, and IFN $\beta$ promote an oxidative burst and the production of hydrogen peroxide $\left(\mathrm{H}_{2} \mathrm{O}_{2}\right)$, as well as blocking TGF $\beta$ pathway. Collectively, $\mathrm{H}_{2} \mathrm{O}_{2}$ triggers the activation and opening of TRPM2, and further leads to a lethal influx of calcium $\left(\mathrm{Ca}^{2+}\right)$ into tumor cells. (B) N2 phenotype promoted the tumor growth, angiogenesis, and immunosuppression. Neutrophils express immune check point receptor of PDL1 and VISTA. They also have been shown expression of ARG1, ROS, and NO in the presence of G-CSF and TGF $\beta$ in TME, which inactivate T cells. HMGB1 from the release of NETs can activate TLR9-depedent pathway which sustain tumor cells proliferation. NE and MMP9 cleave laminin-111, and then cleaved laminin-111 triggers the proliferation of tumor cells through activation of integrin signaling. Neutrophils promote angiogenesis through the release of the pro-angiogenic factors BV8, S100A8/9, and MMP9 that activate VEGFA. TANs, tumor-associated neutrophils; IFN- $\beta$, Interferon- $\beta$; TGF- $\beta$, transforming growth factor- $\beta$; TME, tumor microenvironment; GM-CSF, granulocyte-macrophage colony- stimulating factor; IFN $\gamma$, Interferon- $\gamma$; CXCL5/8, CXC-chemokine ligand

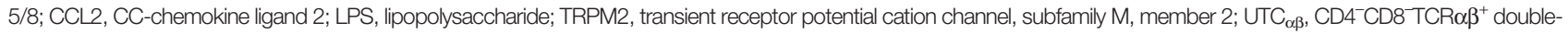
negative unconventional T cells; PDL1, programmed cell death 1 ligand 1;VISTA, and V-domain immunoglobulin suppressor of T cell activation; Arg-1, arginase 1; ROS, reactive oxygen species; NO, nitric oxide; G-CSF, granulocyte colony-stimulating factor; HMGB1, high mobility group protein 1; NETs, Neutrophil extracellular traps; TLR9, Toll-like receptor 9; NE, neutrophil elastase; MMP9 matrix metalloproteinase 9; VEGFA, vascular endothelial growth factor A.

the recruitment, profile and phenotype of other immune cells, especially TAMs and tumor-infiltrating lymphocytes (TIL) which are major components of the immune TME. Neutrophils are reported to exhibit growth-inhibitory activity against early-stage cancers (176-178). Neutrophils are involved in networks of T cell-dependent antitumor immunity. In TME, with the contribution of IFN $\gamma$ and GM-CSF, immature neutrophils become mature and have the function of antigen- 
presenting cells (APCs). Then, these APC-like neutrophils stimulate the proliferation of both $\mathrm{CD} 4+$ and $\mathrm{CD} 8+\mathrm{T}$ cells through the major histocompatibility complex (MHC) class I and class II molecules and the co-stimulatory molecules CD86, 4-1BB ligand (4-1BBL) and OX40 ligand (OX40L) expression (177, 178). Furthermore, chemokine including CXCL10, CCL2, CCL3, CXCL1 and CXCL2 produced by TANs could recruit T cells as well as other leukocytes $(74,179,180)$. Neutrophils are also able to kill tumor cells through direct contact and via ROS generation $(165,176,181)$. The transient receptor potential cation channel, subfamily $\mathrm{M}$, member 2 (TRPM2), a $\mathrm{H}_{2} \mathrm{O}_{2}$ dependent channel, can induce influx of calcium into tumor cells and further lead to cell death. In addition, TNF-related apoptosis inducing ligand (TRAIL) and TNF can induce the expression of the hepatocyte growth factor receptor (HGFR; also known as MET) on neutrophils (182). HGF present in the TME induce neutrophil recruitment and production of nitric oxide (NO), which results in killing of tumor cells (182). Neutrophils also engage in an interaction between macrophages and a subset of unconventional T cells (UTCs), known as CD4 $4^{-} \mathrm{CD} 8^{-} \mathrm{TCR} \alpha \beta+$ double-negative UTCs $\left(\mathrm{UTC}_{\alpha \beta}\right)$. The UTCs were essential for effective antitumor immunity (179). Neutrophils are able to enhance the production of IL-12 by macrophages, and then promote $\mathrm{UTC}_{\alpha \beta}$ polarize towards a type 1 immune response and IFN $\gamma$ production (179). However, the roles, mechanisms, significance of $\mathrm{UTC}_{\alpha \beta}$ in human tumors still need to be elucidated.

In contrast, the strong immunosuppressive activity of neutrophils is associated with polymorphonuclear myeloidderived suppressor cells (MDSCs) in advanced-stage cancer. Polymorphonuclear MDSCs also share features with immature neutrophils. Recently, early neutrophil progenitor was reported to exhibit pro-tumor activity $(173,177,183)$. The disease stage, the tumor type, and tissue context are all key determinants of neutrophils in promoting or restraining cancer. Neutrophils with intrinsic anti-tumor activity are recruited to the tumor, where they are reprogrammed to an immunosuppressive pro-tumor phenotype (from N1 to N2) $(165,173)$.

The ability of cancer-related neutrophils to release NETs has piqued the interest of the scientific community. NETs, which are released from neutrophils in response to extracellular pathogens, typically comprise fibrous decondensed chromatin with associated histones, MPO, and various cytoplasmic proteins, such as neutrophil elastase, cathepsin G, and lactoferrin. Although NETs are reported to be released in response to cancer cells, their role in cancer is not clear.

NETs, the release of ROS, and the trapping of cancer cells could theoretically promote a cytotoxic effect and inhibit the dissemination of cancer cells $(184,185)$. However, most studies have only described this phenomenon in circulating neutrophils (186-188). Some studies have also reported that NETs are spontaneously produced in samples from patients with cancer and that NETs promote metastatic dissemination after surgical stress (187). In mouse models, sustained lung inflammation caused by tobacco smoke exposure or nasal instillation of lipopolysaccharide leads to NETs formation (189). Neutrophil elastase and matrix metalloproteinase 9 (NET-associated proteases) cleave the extracellular matrix protein laminin. The proteolytically remodeled laminin induced proliferation of dormant cancer cells by activating integrin $\alpha 3 \beta 1$ signaling. Then, the dormant cancer cells are awakening to aggressively growing metastases. Therefore, NETs are hypothesized to act within the primary tumor to promote disease progression and dissemination. The enhanced release of NETs by the neutrophils has been suggested to promote tumor progression and metastatic dissemination. Thus, further studies are needed to clarify the pro-tumor and anti-tumor functions of NETs in glioma and BMs.

Macrophages are the major infiltrating immune cells (up to $30 \%$ tumor mass) in the brain TME (190). Thus, there was increased focus on macrophages in the brain TME in the past few years. However, one study reported that neutrophils infiltrate the human glioma and the degree of infiltration was markedly correlated with tumor grade (191). However, the mechanism of neutrophil recruitment and the role of neutrophils in tumor growth have not been elucidated. Most studies on neutrophils and brain tumors have focused on the impact of these cells on the response to anti-angiogenic therapy and vascularization (a hallmark of high-grade glioma). Enhanced neutrophil infiltration into tumor tissue is associated with acquired resistance to the vascular endothelial growth factor antibody (bevacizumab) and high glioma grade at advanced stages (191, 192). Preclinical studies have demonstrated that neutrophils contribute to glioblastoma progression by supporting the expansion of the glioma stem cell pool through S100 proteindependent mechanism (192). S100 proteins are associated with secondary dissemination, especially the dissemination of breast cancer (193). S100A8 and S100A9, which are upregulated in the pre-metastatic brain, promote the recruitment of neutrophils and subsequently promote metastatic seeding (194). The brain may be aberrantly exposed to pathological inflammation associated with the tumor that influences disease progression. Therefore, future studies must focus on the mechanisms of neutrophil infiltration in the brain TME.

\section{NEUTROPHIL AS A THERAPEUTIC TARGET AND POTENTIAL COMBINATION OF NEUTROPHIL-TARGETING WITH OTHER CANCER THERAPIES}

Traditionally, neutrophils were not considered to have a critical role in the TME. However, recent studies have demonstrated that (195-197) neutrophils play a major role in the pathogenesis of cancer, including tumor initiation, development, and progression. Furthermore, several studies have suggested that the presence and phenotype of neutrophils in the TME determine the outcomes of traditional and novel therapies, such as ICIs $(198,199)$. Most studies indicate that neutrophils promote tumorigenesis $(167,200)$. Therefore, neutrophils can be directly targeted to inhibit their recruitment, activation, or 
phenotype reprograming. Recently, the concept of targeting TANs has been proposed by several studies. The polarization of neutrophils (pro-tumor or anti-tumor) in cancers must be characterized to improve the efficacy of therapeutic modalities. Therefore, the development of next-generation immunotherapies is an important topic of research (201). Various approaches have been developed to therapeutically target neutrophils, including strategies to enhance, inhibit, or reprogram the neutrophil phenotype. Clinical trials on TGF $\beta$ pathway inhibitors and PDE5 inhibitors for glioma and BMs are ongoing. However, there are several challenges and controversies for using these strategies. For example, Galunisertib, a novel TGF $\beta$ receptor 1 kinase inhibitor, is currently undergoing clinical trials as a monotherapy or in combination with lomustine chemotherapy in two clinical trials involving patients with recurrent glioblastoma (NCT01582269 and NCT01682187) and those undergoing temozolomide-based chemoradiotherapy (NCT01220271). Here, we have listed some therapeutic mechanisms that potentially recruit, activate, inhibit, or modulate the phenotypes of neutrophils in the TME, which are currently being investigated in cancers of humans or animals (Figure 3A, Table 1).

\section{Combining Neutrophil-Targeting Therapy With Other Anticancer Therapies}

Several chemotherapies are reported to cause neutropenia and consequently eliminate neutrophils from the TME. However, the effect of these chemotherapies on the neutrophil phenotype modulation and the subsequent implications in treatment efficacy are largely unknown. These patients are at an increased risk of opportunistic infections (211, 212). Furthermore, neutrophils are a key mediator of the efficacy, clinical value, and toxicity of these therapies in patients receiving ICIs (213).
However, limited studies have focused on the effects of drugs on cancer-related neutrophil phenotypes. A critical assessment of the most optimal combination therapy strategies is key for the successful clinical implementation of neutrophil-targeting approaches. Various mechanistic studies performed in clinically relevant mouse tumor models have addressed the impact of neutrophils on the efficacy of anticancer therapies.

\section{Chemotherapy}

Neutropenia is a common "adverse effect" of chemotherapy (214). In the clinics, recombinant G-CSF and GM-CSF are commonly prescribed to increase neutrophil counts and reduce the risk of infection as they promote the release of neutrophils from the bone marrow $(22,215)$. However, the effects of G-CSF or GM-CSF on human neutrophil phenotypes are unclear. Contradictory findings have been reported for the pro-tumor and anti-tumor activities of the recruited neutrophils.

In vitro studies on neutrophils isolated from the peripheral blood of patients who received G-CSF have revealed contradictory findings on neutrophil function, including phagocytosis, oxidative burst, bacterial killing, and chemotaxis (216). Filgrastim (non-glycosylated G-CSF) and lenograstim (glycosylated G-CSF) exhibited differential effects on the chemotaxis and morphology of circulating neutrophils isolated from patients with non-Hodgkin lymphoma (217). Neutrophils from patients who received lenograstim exhibited impaired chemotaxis. In contrast, neutrophils isolated from patients who received filgrastim had a morphology that suggested enhanced activation and upregulated expression of integrin $\beta 2$. G-CSF and GM-CSF, which are reported to exert pro-tumor and anti-tumor effects, can affect both tumor and immune cells (218-222). Previous studies have reported that G-CSF induces the
A

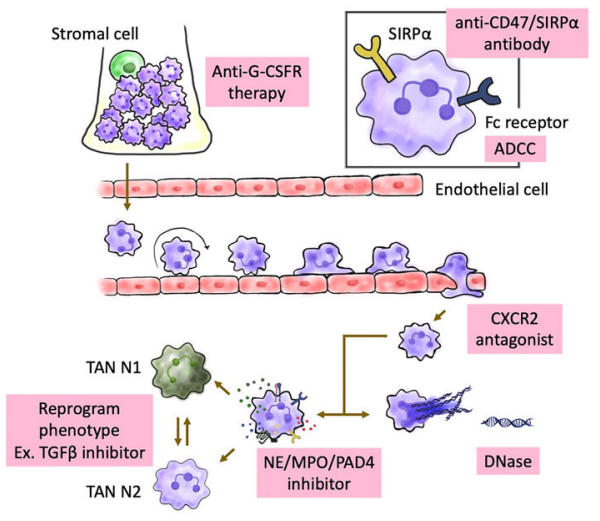

B

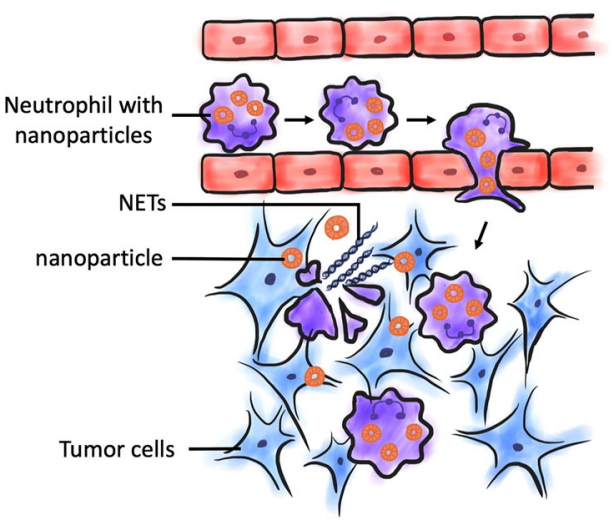

FIGURE 3 | Possible treatment targeting neutrophils in brain tumors. (A) Several aspects of neutrophil biological function may be therapeutically targeted from the maturation process to effector functions. The targeting aims are to enhance or inhibit neutrophil function, or to restore normal neutrophil function. Enhancement can be achieved by inhibiting signal-regulatory protein $\alpha(\mathrm{SIRP} \alpha)$. Inhibitors of CXCR1, CXCR2 can be used to block neutrophil activation and migration. NE, MPO, and PAD4 inhibitors can be used inhibit NETosis. (B) Neutrophils can be nanocarrier to mediate anticancer nanoparticle drug delivery. After surgical resection of brain tumors, inflammatory signals were amplified at post-resection sites, which attracted neutrophils with nanoparticles to migrate into infiltrating brain tumors along the chemotactic gradient, and results in disruption of the neutrophils and release of NETs. That renders a concomitant release drug into tumor microenvironment and produce antitumor effect. NETs were also released on excessive activation by inflammatory cytokines. G-CSFR, G-CSF receptor; MPO, myeloperoxidase; NE, neutrophil elastase; NET, neutrophil extracellular trap; PAD4, peptidylarginine deiminase 4; TAN, tumor-associated neutrophil. 
TABLE 1 | Agents with putative effects on neutrophils in patients with cancer.

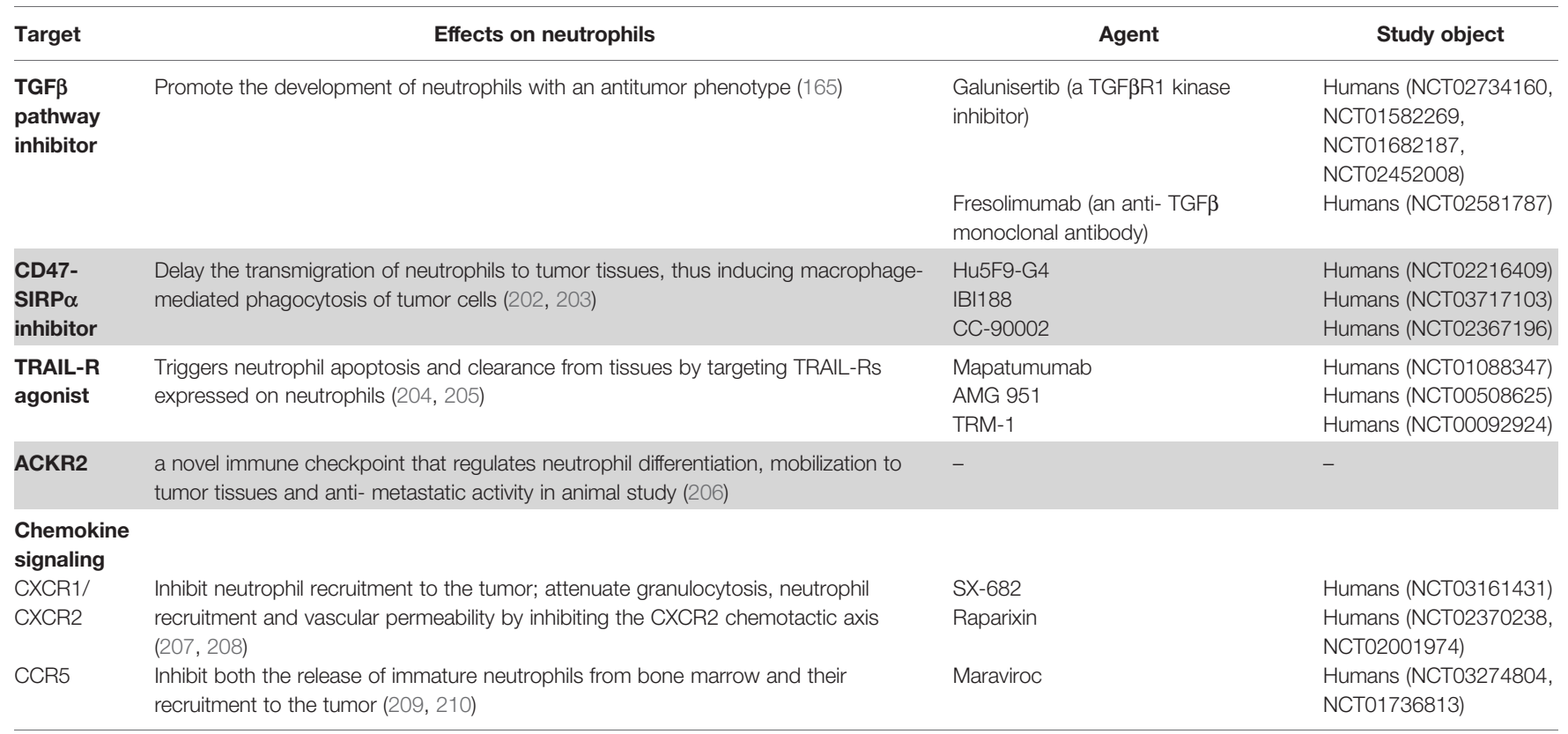

phagocytic and antibacterial activities of neutrophils (223) and promotes ROS production upon stimulation (224). However, the phenotypic modulation of TANs after treatment with G-CSF and GM-CSF is currently under investigation.

\section{Radiotherapy}

Radiotherapy is one of the most important treatment modalities for cancer. Several studies on animal models have demonstrated that radiotherapy activates both the adaptive and innate immune responses through the release of antigens, Toll-like receptor ligands, and pro-inflammatory cytokines from tumor cells. This promotes the recruitment of myeloid cells, such as macrophages, dendritic cells, and neutrophils, and induces $\mathrm{T}$ cell-mediated immunogenic cell death (225-227). In preclinical models, radiotherapy induces sterile inflammation with rapid and transient infiltration of neutrophils into the tumors (228). These newly recruited neutrophils produce increased amounts of ROS and induce apoptosis in the tumor cells. Recent studies have suggested that the baseline blood neutrophil count is correlated with the survival of patients with different cancers after radiotherapy (229232). However, limited studies have examined the effects of radiation on neutrophil phenotypes in patients with cancer. Clinical studies have demonstrated that radiotherapy can initiate a response outside the local radiation field (which is known as the "abscopal effect") and this is correlated with enhanced recruitment of immune cells (233-236). Based on these observations, the combination of radiotherapy and immunotherapy or GM-CSF may improve the clinical outcomes of patients with cancer (237239). The effects of radiotherapy on human neutrophils are unknown (229).

\section{ICIs}

ICIs, such as anti-CTLA-4 and anti-PD-1 antibodies, exhibited satisfactory therapeutic efficacy in several patients with advanced-stage cancers, especially in patients with melanoma. Although not all patients benefit from these agents, ICIs are frequently used as first-line therapies in patients with other cancers $(240,241)$ exhibiting upregulated expression of PD-1, PD-L1, and/or CTLA-4. Several studies have reported the effects of ICIs on the TME in mouse models (242) and patients with cancer (243-245). However, the effects of ICIs on intratumoral neutrophils remain unclear.

In a study published in 2017, changes in intratumoral immune cell subpopulations were investigated in patients with melanoma after treatment with the anti-PD-1 antibody nivolumab (243). The number of intratumoral neutrophils was not markedly different between patients who benefited from nivolumab and those who did not benefit from nivolumab although the intratumoral neutrophil counts varied between the two groups. Several studies have suggested a correlation between PD-L1 expression on neutrophils and an immunosuppressive phenotype. For example, PD-L1+ neutrophils are reported to suppress $\mathrm{T}$ cell function and promote disease progression in patients with gastric cancer (199). This suppressive effect may be reversed upon inhibition of PD-L1. The expression levels of PD-L1 in the intratumoral and peritumoral neutrophils were upregulated when compared with those in circulating neutrophils in patients with hepatocellular carcinoma (198). This suggested that TANs exert strong immunosuppressive effects in these patients and that PD-L1+ neutrophils are potential targets of anti-PD-1 and/ or anti-PD-L1 antibodies.

\section{Targeting NETs}

NETs, which are involved in antimicrobial immunity, autoimmune conditions, cardiovascular diseases, and tumor progression $(66,198,246)$, are a potential therapeutic target for cancer. In several cases, NET formation is dependent on the 
activity of NADPH oxidase. Thus, the inhibition of NADPH oxidase can alter NETosis (175). Superoxide can be transformed into hydrogen peroxide, which can activate azurophilic (primary) granule proteins, such as neutrophil elastase or MPO (175) and consequently promote the nuclear translocation of some molecules. In the nucleus, neutrophil elastase promotes nuclear decondensation. MPO upregulates the activity of neutrophil elastase. Hence, neutrophil elastase and MPO can serve as therapeutic targets for NET-associated disorders $(247,248)$. Neutrophil elastase inhibitors are effective in patients with bronchiectasis. Currently, studies on the therapeutic potential of neutrophil elastase inhibitors for bronchiolitis obliterans are ongoing (249). As PAD4 is critical for NET formation, it is a potential therapeutic target for NETmediated diseases (250-252). The effect of PAD inhibitors on human patients has not been examined. Previous studies have targeted DNase I to alleviate NET-mediated pathology (253256). Therefore, DNase I-mediated degradation of NETs can be a potential therapeutic strategy for cancers with NET involvement.

\section{NEUTROPHIL AS A NANOCARRIER}

Surgical resection is the major therapeutic strategy for brain tumors (257). However, the infiltrating tumor cells near the eloquent brain area should not be completely removed to preserve neurological functions (258). Generally, adjuvant chemotherapy is necessary after surgery. However, the efficacy of adjuvant therapy is limited owing to poor drug penetration caused due to various physiological barriers, especially the bloodbrain barrier (BBB) and blood-tumor barrier (BTB) (259-261), which contribute to tumor recurrence. Therefore, nanoparticlebased drug delivery systems (NDDSs) are used for enhanced targeting of the tumor (262-265). NDDSs utilize active targeting ligands or passive leakage of tumor vasculature (266-269). However, the efficacy of these NDDSs for postoperative glioma treatment is poor due to a low half-life of the nanoparticles in the circulation, insufficient intratumoral drug accumulation, and severe systemic toxicity.

Recently, cell-based drug delivery systems are considered powerful bioinspired drug delivery platforms for glioma (269274). Vectorization of therapeutic agents using endogenous cells has been proposed as a potential strategy for targeted drug delivery to the brain (275-277). Neutrophils, which play a critical role in immune responses, can be activated within the vasculature. The activated neutrophils move along chemotactic gradients toward the inflammatory sites and eliminate the pathogens by phagocytosis (278-280). Additionally, neutrophils can cross the BBB/BTB and infiltrate the tumor mass $(191,281-283)$. TANs, which are distributed in the glioma region (284), promote the continuous recruitment of the circulating neutrophils (201). Surgical tumor excision leads to local brain inflammation with the release of inflammatory factors, such as IL-8 $(285,286)$ and TNF- $\alpha$ (287, 288) that activate the migration of neutrophils to the inflamed region of the brain (278). The amplification of inflammatory signals supports enhanced targeting of brain tumors.
Therefore, neutrophils could be explored as "Trojan horses" to carry concealed drug cargoes to diseased brain areas (Figure 3B). Zhang et al. demonstrated that the physiological activity of neutrophils carrying PTX liposomes was not affected and that these neutrophils migrate to the inflamed brain tumor. These neutrophils improved the survival of postsurgical gliomabearing mice (289). Traditional nanoparticles passively target the tumor site [which is known as the enhanced permeability and retention effect (290)] or actively target the tumor site through ligand-receptor interactions (291). In contrast, the neutrophilmediated drug delivery system can recognize postoperative inflammatory signals, such as IL-8 and CXCL1/KC $(74,292)$ and spontaneously deliver chemotherapeutics to infiltrating glioma cells. The aberrant activation of neutrophils by the upregulated inflammatory cytokines in the inflamed brain results in the disruption of neutrophils and promotes the release of NETs (293) with concomitant release of liposomes to deliver PTX into the remaining infiltrating tumor cells. We believe this strategy will offer new opportunities to explore endogenous immunocytes as drug delivery vehicles. In the future, neutrophils harvested from humans can be used to deliver drugs in clinics.

Several challenges associated with nanoparticle delivery systems must be addressed before translation into a human clinical model. The extraction of neutrophils from patients before intracranial implantation may pose an additional risk and delay surgery. The bioactivity of PTXCL within neutrophils in vivo remains unclear. The PTX resistance of glioma cells (as evidenced by the poor efficacy of PTX-CL/NE treatment) suggests that combination treatment must be considered to attain optimal therapeutic efficacy. However, neutrophilmediated DDSs targeting the glioma-initiating stem cells in the perivascular niche can have potent therapeutic benefits (294, 295).

\section{CONCLUSION AND PERSPECTIVE}

The role of neutrophils in cancer biology and their potential as therapeutic targets have been widely recognized. Recent studies have demonstrated the important biological roles of neutrophils. The complex roles of neutrophils in cancer include their ability to exert pro-tumor or anti-tumor activities and to exhibit various polarization phenotypes. The elucidation of the interaction of neutrophils in cancer can aid in the development of novel therapeutic interventions. For example, targeting TANs and/or circulating neutrophils can be potential next-generation immunotherapies. However, further studies are needed to examine the exact roles, recruitment pathways, subpopulations, and mechanisms of action of TANs to develop targeted therapeutic approaches. Additionally, the role of TANs in the brain TME is not clear although the extent of neutrophil infiltration is correlated with glioma grades. Thus, TANs in the brain TME are a potential therapeutic target for brain cancer. Additionally, TANs can improve the efficacy of chemotherapy or immunotherapy. 
There are contradictory reports on several characteristics of neutrophils, including lifespan, transcriptional activity, roles in cancer, and subpopulation types. Additionally, neutrophils may escape therapeutic interventions because of their exceptional turnover and unexpected plasticity, especially in cancer. However, recent understanding of neutrophil biology has revealed that precise therapeutic interventions may provide therapeutic benefits without detrimental side effects. In particular, NETs are a key therapeutic target (296). Future studies must focus on small-molecule and biological therapeutics that can regulate the neutrophil compartment to promote the activation, inhibition, or depletion of neutrophils. Additionally, antibody-mediated delivery of small molecules can be a potential therapeutic strategy. Recent studies have suggested the potential applications of neutrophils as drug-trafficking cells (289, 297). Neutrophil-derived molecules, such as granule proteins and peptides may also be used as therapeutic agents under certain conditions. In summary, these findings indicate the potential of targeting neutrophils in human diseases.

\section{REFERENCES}

1. Ehrlich P. Methodologische Beitrage Zur Physiologie Und Pathologie Der Verschiedenen Formen Der Leukocyten. Klin Med (1880) 1:553-8.

2. Coffelt SB, Wellenstein MD, de Visser KE. Neutrophils in Cancer: Neutral No More. Nat Rev Cancer (2016) 16:431-46. doi: 10.1038/nrc.2016.52

3. Németh T, Sperandio M, Mócsai A. Neutrophils as Emerging Therapeutic Targets. Nat Rev Drug Discovery (2020) 19:253-75. doi: 10.1038/s41573-019-0054-Z

4. Leliefeld PH, Koenderman L, Pillay J. How Neutrophils Shape Adaptive Immune Responses. Front Immunol (2015) 6:471. doi: 10.3389/ fimmu.2015.00471

5. Rosales C, Lowell CA, Schnoor M, Uribe-Querol E. Neutrophils: Their Role in Innate and Adaptive Immunity 2017. J Immunol Res (2017) 2017:9748345. doi: 10.1155/2017/9748345

6. Chiang CC, Cheng WJ, Korinek M, Lin CY, Hwang TL. Neutrophils in Psoriasis. Front Immunol (2019) 10:2376. doi: 10.3389/fimmu.2019.02376

7. Balkwill F, Mantovani A. Inflammation and Cancer: Back to Virchow? Lancet (2001) 357:539-45. doi: 10.1016/S0140-6736(00)04046-0

8. Mantovani A, Allavena P, Sica A, Balkwill F. Cancer-Related Inflammation. Nature (2008) 454:436-44. doi: 10.1038/nature07205

9. Hanahan D, Weinberg RA. Hallmarks of Cancer: The Next Generation. Cell (2011) 144:646-74. doi: 10.1016/j.cell.2011.02.013

10. Lim M, Xia Y, Bettegowda C, Weller M. Current State of Immunotherapy for Glioblastoma. Nat Rev Clin Oncol (2018) 15:422-42. doi: 10.1038/s41571-0180003-5

11. Louveau A, Smirnov I, Keyes TJ, Eccles JD, Rouhani SJ, Peske JD, et al. Structural and Functional Features of Central Nervous System Lymphatic Vessels. Nature (2015) 523:337-41. doi: 10.1038/nature14432

12. Burnet M. Cancer: A Biological Approach: III. Viruses Associated With Neoplastic Conditions: IV. Practical Applications. Br Med J (1957) 1:841-7. doi: 10.1136/bmj.1.5023.841

13. Burnet FM. The Concept of Immunological Surveillance. Prog Exp Tumor Res (1970) 13:1-27. doi: 10.1159/000386035

14. Thomas L. Cellular and Humoral Aspects of the Hypersensitive States. Acta Med Scand (1961) 170:128-8. doi: 10.1111/j.0954-6820.1961.tb00220.x

15. Dunn GP, Old LJ, Schreiber RD. The Immunobiology of Cancer Immunosurveillance and Immunoediting. Immunity (2004) 21:137-48. doi: 10.1016/j.immuni.2004.07.017

16. Ribas A, Wolchok JD. Cancer Immunotherapy Using Checkpoint Blockade. Science (2018) 359:1350-5. doi: 10.1126/science.aar4060

17. Medikonda R, Dunn G, Rahman M, Fecci P, Lim M. A Review of Glioblastoma Immunotherapy. J Neurooncol (2021) 151:41-53. doi: 10.1007/s11060-020-03448-1

\section{AUTHOR CONTRIBUTIONS}

Y-JL, ML, and T-LH wrote and revised the manuscript. K-CW and P-YC consulted and revised the manuscript. Y-JL drew the figures. ML and T-LH initiated the concept and supervised the writing. All authors contributed to the article and approved the submitted version.

\section{FUNDING}

This study is sponsored by Chang Gung Memorial Hospital (grants CMRPG3H1141). The sponsor had no role in the design or conduct of this research.

\section{ACKNOWLEDGMENTS}

The authors thank Li-Ting Huang for drawing the figures.

18. Ng LG, Ostuni R, Hidalgo A. Heterogeneity of Neutrophils. Nat Rev Immunol (2019) 19:255-65. doi: 10.1038/s41577-019-0141-8

19. Shaul ME, Fridlender ZG. Tumour-Associated Neutrophils in Patients With Cancer. Nat Rev Clin Oncol (2019) 16:601-20. doi: 10.1038/s41571-0190222-4

20. Dancey JT, Deubelbeiss KA, Harker LA, Finch CA. Neutrophil Kinetics in Man. J Clin Invest (1976) 58:705-15. doi: 10.1172/JCI108517

21. Borregaard N. Neutrophils, From Marrow to Microbes. Immunity (2010) 33:657-70. doi: 10.1016/j.immuni.2010.11.011

22. Manz MG, Boettcher S. Emergency Granulopoiesis. Nat Rev Immunol (2014) 14:302-14. doi: 10.1038/nri3660

23. Görgens A, Radtke S, Möllmann M, Cross M, Dürig J, Horn PA, et al. Revision of the Human Hematopoietic Tree: Granulocyte Subtypes Derive From Distinct Hematopoietic Lineages. Cell Rep (2013) 3:1539-52. doi: 10.1016/j.celrep.2013.04.025

24. Friedman AD. Transcriptional Control of Granulocyte and Monocyte Development. Oncogene (2007) 26:6816-28. doi: 10.1038/sj.onc.1210764

25. Fiedler K, Brunner C. The Role of Transcription Factors in the Guidance of Granulopoiesis. Am J Blood Res (2012) 2:57-65.

26. Rosenbauer F, Tenen DG. Transcription Factors in Myeloid Development: Balancing Differentiation With Transformation. Nat Rev Immunol (2007) 7:105-17. doi: $10.1038 /$ nri2024

27. Pillay J, Tak T, Kamp VM, Koenderman L. Immune Suppression by Neutrophils and Granulocytic Myeloid-Derived Suppressor Cells: Similarities and Differences. Cell Mol Life Sci (2013) 70:3813-27. doi: 10.1007/s00018-013-1286-4

28. Häger M, Cowland JB, Borregaard N. Neutrophil Granules in Health and Disease. J Intern Med (2010) 268:25-34. doi: 10.1111/j.1365-2796. 2010.02237.x

29. Borregaard N, Sørensen OE, Theilgaard-Mönch K. Neutrophil Granules: A Library of Innate Immunity Proteins. Trends Immunol (2007) 28:340-5. doi: 10.1016/j.it.2007.06.002

30. Lieschke GJ, Grail D, Hodgson G, Metcalf D, Stanley E, Cheers C, et al. Mice Lacking Granulocyte Colony-Stimulating Factor Have Chronic Neutropenia, Granulocyte and Macrophage Progenitor Cell Deficiency, and Impaired Neutrophil Mobilization. Blood (1994) 84:1737-46. doi: 10.1182/blood.V84.6.1737.1737

31. Liu F, Wu HY, Wesselschmidt R, Kornaga T, Link DC. Impaired Production and Increased Apoptosis of Neutrophils in Granulocyte Colony-Stimulating Factor Receptor-Deficient Mice. Immunity (1996) 5:491-501. doi: 10.1016/ S1074-7613(00)80504-X

32. Richards MK, Liu F, Iwasaki H, Akashi K, Link DC. Pivotal Role of Granulocyte Colony-Stimulating Factor in the Development of 
Progenitors in the Common Myeloid Pathway. Blood (2003) 102:3562-8. doi: 10.1182/blood-2003-02-0593

33. McKinstry WJ, Li CL, Rasko JE, Nicola NA, Johnson GR, Metcalf D. Cytokine Receptor Expression on Hematopoietic Stem and Progenitor Cells. Blood (1997) 89:65-71. doi: 10.1182/blood.V89.1.65.65_65_71

34. Adolfsson J, Månsson R, Buza-Vidas N, Hultquist A, Liuba K, Jensen CT, et al. Identification of Flt3+ Lymphomyeloid Stem Cells Lacking ErythroMegakaryocytic Potential a Revised Road Map for Adult Blood Lineage Commitment. Cell (2005) 121:295-306. doi: 10.1016/j.cell.2005.02.013

35. Panopoulos AD, Zhang L, Snow JW, Jones DM, Smith AM, El Kasmi KC, et al. STAT3 Governs Distinct Pathways in Emergency Granulopoiesis and Mature Neutrophils. Blood (2006) 108:3682-90. doi: 10.1182/blood-200602-003012

36. Molineux G, Migdalska A, Szmitkowski M, Zsebo K, Dexter TM. The Effects on Hematopoiesis of Recombinant Stem Cell Factor (Ligand for C-Kit) Administered In Vivo to Mice Either Alone or in Combination With Granulocyte Colony-Stimulating Factor. Blood (1991) 78:961-6. doi: 10.1182/blood.V78.4.961.bloodjournal784961

37. Liu F, Poursine-Laurent J, Wu HY, Link DC. Interleukin-6 and the Granulocyte Colony-Stimulating Factor Receptor Are Major Independent Regulators of Granulopoiesis In Vivo But Are Not Required for Lineage Commitment or Terminal Differentiation. Blood (1997) 90:2583-90. doi: 10.1182/blood.V90.7.2583.2583_2583_2590

38. Seymour JF, Lieschke GJ, Grail D, Quilici C, Hodgson G, Dunn AR. Mice Lacking Both Granulocyte Colony-Stimulating Factor (CSF) and Granulocyte-Macrophage CSF Have Impaired Reproductive Capacity, Perturbed Neonatal Granulopoiesis, Lung Disease, Amyloidosis, and Reduced Long-Term Survival. Blood (1997) 90:3037-49. doi: 10.1182/ blood.V90.8.3037

39. Casbon AJ, Reynaud D, Park C, Khuc E, Gan DD, Schepers K, et al. Invasive Breast Cancer Reprograms Early Myeloid Differentiation in the Bone Marrow to Generate Immunosuppressive Neutrophils. Proc Natl Acad Sci USA (2015) 112:E566-75. doi: 10.1073/pnas.1424927112

40. Coffelt SB, Kersten K, Doornebal CW, Weiden J, Vrijland K, Hau CS, et al. IL-17-Producing Gammadelta T Cells and Neutrophils Conspire to Promote Breast Cancer Metastasis. Nature (2015) 522:345-8. doi: 10.1038/ nature 14282

41. Waight JD, Hu Q, Miller A, Liu S, Abrams SI. Tumor-Derived G-CSF Facilitates Neoplastic Growth Through a Granulocytic Myeloid-Derived Suppressor Cell-Dependent Mechanism. PloS One (2011) 6:e27690. doi: 10.1371/journal.pone.0027690

42. Kowanetz M, Wu X, Lee J, Tan M, Hagenbeek T, Qu X, et al. GranulocyteColony Stimulating Factor Promotes Lung Metastasis Through Mobilization of Ly6G+Ly6C+ Granulocytes. Proc Natl Acad Sci USA (2010) 107:2124855. doi: 10.1073/pnas.1015855107

43. Bayne LJ, Beatty GL, Jhala N, Clark CE, Rhim AD, Stanger BZ, et al. TumorDerived Granulocyte-Macrophage Colony-Stimulating Factor Regulates Myeloid Inflammation and T Cell Immunity in Pancreatic Cancer. Cancer Cell (2012) 21:822-35. doi: 10.1016/j.ccr.2012.04.025

44. Pylayeva-Gupta Y, Lee KE, Hajdu CH, Miller G, Bar-Sagi D. Oncogenic Kras-Induced GM-CSF Production Promotes the Development of Pancreatic Neoplasia. Cancer Cell (2012) 21:836-47. doi: 10.1016/ j.ccr.2012.04.024

45. Kuonen F, Laurent J, Secondini C, Lorusso G, Stehle JC, Rausch T, et al. Inhibition of the Kit Ligand/C-Kit Axis Attenuates Metastasis in a Mouse Model Mimicking Local Breast Cancer Relapse After Radiotherapy. Clin Cancer Res (2012) 18:4365-74. doi: 10.1158/1078-0432.CCR-11-3028

46. Semerad CL, Liu F, Gregory AD, Stumpf K, Link DC. G-CSF Is an Essential Regulator of Neutrophil Trafficking From the Bone Marrow to the Blood. Immunity (2002) 17:413-23. doi: 10.1016/S1074-7613(02)00424-7

47. Ma Q, Jones D, Springer TA. The Chemokine Receptor CXCR4 Is Required for the Retention of B Lineage and Granulocytic Precursors Within the Bone Marrow Microenvironment. Immunity (1999) 10:463-71. doi: 10.1016/ S1074-7613(00)80046-1

48. Martin C, Burdon PC, Bridger G, Gutierrez-Ramos JC, Williams TJ, Rankin SM. Chemokines Acting via CXCR2 and CXCR4 Control the Release of Neutrophils From the Bone Marrow and Their Return Following
Senescence. Immunity (2003) 19:583-93. doi: 10.1016/S1074-7613(03) 00263-2

49. Suratt BT, Petty JM, Young SK, Malcolm KC, Lieber JG, Nick JA, et al. Role of the CXCR4/SDF-1 Chemokine Axis in Circulating Neutrophil Homeostasis. Blood (2004) 104:565-71. doi: 10.1182/blood-2003-10-3638

50. Eash KJ, Means JM, White DW, Link DC. CXCR4 Is a Key Regulator of Neutrophil Release From the Bone Marrow Under Basal and Stress Granulopoiesis Conditions. Blood (2009) 113:4711-9. doi: 10.1182/blood2008-09-177287

51. Eash KJ, Greenbaum AM, Gopalan PK, Link DC. CXCR2 and CXCR4 Antagonistically Regulate Neutrophil Trafficking From Murine Bone Marrow. J Clin Invest (2010) 120:2423-31. doi: 10.1172/JCI41649

52. Köhler A, De Filippo K, Hasenberg M, van den Brandt C, Nye E, Hosking MP, et al. G-CSF-Mediated Thrombopoietin Release Triggers Neutrophil Motility and Mobilization From Bone Marrow via Induction of Cxcr2 Ligands. Blood (2011) 117:4349-57. doi: 10.1182/blood-2010-09-308387

53. Levesque JP, Liu F, Simmons PJ, Betsuyaku T, Senior RM, Pham C, et al. Characterization of Hematopoietic Progenitor Mobilization in ProteaseDeficient Mice. Blood (2004) 104:65-72. doi: 10.1182/blood-2003-05-1589

54. Burdon PC, Martin C, Rankin SM. The CXC Chemokine MIP-2 Stimulates Neutrophil Mobilization From the Rat Bone Marrow in a CD49dDependent Manner. Blood (2005) 105:2543-8. doi: 10.1182/blood-200408-3193

55. Petty JM, Lenox CC, Weiss DJ, Poynter ME, Suratt BT. Crosstalk Between CXCR4/stromal Derived Factor-1 and VLA-4/VCAM-1 Pathways Regulates Neutrophil Retention in the Bone Marrow. J Immunol (2009) 182:604-12. doi: 10.4049/jimmunol.182.1.604

56. Wengner AM, Pitchford SC, Furze RC, Rankin SM. The Coordinated Action of G-CSF and ELR + CXC Chemokines in Neutrophil Mobilization During Acute Inflammation. Blood (2008) 111:42-9. doi: 10.1182/blood-2007-07099648

57. Acharyya S, Oskarsson T, Vanharanta S, Malladi S, Kim J, Morris PG, et al. A CXCL1 Paracrine Network Links Cancer Chemoresistance and Metastasis. Cell (2012) 150:165-78. doi: 10.1016/j.cell.2012.04.042

58. Mócsai A, Walzog B, Lowell CA. Intracellular Signalling During Neutrophil Recruitment. Cardiovasc Res (2015) 107:373-85. doi: 10.1093/cvr/cvv159

59. Futosi K, Fodor S, Mócsai A. Neutrophil Cell Surface Receptors and Their Intracellular Signal Transduction Pathways. Int Immunopharmacol (2013) 17:638-50. doi: 10.1016/j.intimp.2013.06.034

60. Winterbourn CC, Kettle AJ. Redox Reactions and Microbial Killing in the Neutrophil Phagosome. Antioxid Redox Signal (2013) 18:642-60. doi: 10.1089/ars.2012.4827

61. Stapels DA, Geisbrecht BV, Rooijakkers SH. Neutrophil Serine Proteases in Antibacterial Defense. Curr Opin Microbiol (2015) 23:42-8. doi: 10.1016/ j.mib.2014.11.002

62. Cowland JB, Borregaard N. Granulopoiesis and Granules of Human Neutrophils. Immunol Rev (2016) 273:11-28. doi: 10.1111/imr.12440

63. Németh T, Mócsai A. Feedback Amplification of Neutrophil Function. Trends Immunol (2016) 37:412-24. doi: 10.1016/j.it.2016.04.002

64. Reeves EP, Lu H, Jacobs HL, Messina CG, Bolsover S, Gabella G, et al. Killing Activity of Neutrophils Is Mediated Through Activation of Proteases by K+ Flux. Nature (2002) 416:291-7. doi: 10.1038/416291a

65. Brinkmann V, Reichard U, Goosmann C, Fauler B, Uhlemann Y, Weiss DS, et al. Neutrophil Extracellular Traps Kill Bacteria. Science (2004) 303:1532-5. doi: $10.1126 /$ science. 1092385

66. Daniel C, Leppkes M, Muñoz LE, Schley G, Schett G, Herrmann M. Extracellular DNA Traps in Inflammation, Injury and Healing. Nat Rev Nephrol (2019) 15:559-75. doi: 10.1038/s41581-019-0163-2

67. Porto BN, Stein RT. Neutrophil Extracellular Traps in Pulmonary Diseases: Too Much of a Good Thing? Front Immunol (2016) 7:311. doi: 10.3389/ fimmu.2016.00311

68. Sollberger G, Choidas A, Burn GL, Habenberger P, Di Lucrezia R, Kordes S, et al. Gasdermin D Plays a Vital Role in the Generation of Neutrophil Extracellular Traps. Sci Immunol (2018) 3:eaar6689. doi: 10.1126/ sciimmunol.aar6689

69. Chen KW, Monteleone M, Boucher D, Sollberger G, Ramnath D, Condon ND, et al. Noncanonical Inflammasome Signaling Elicits Gasdermin D- 
Dependent Neutrophil Extracellular Traps. Sci Immunol (2018) 3:eaar6676. doi: 10.1126/sciimmunol.aar6676

70. Jiménez-Alcázar M, Rangaswamy C, Panda R, Bitterling J, Simsek YJ, Long AT, et al. Host DNases Prevent Vascular Occlusion by Neutrophil Extracellular Traps. Science (2017) 358:1202-6. doi: 10.1126/science. aam8897

71. Kovács M, Németh T, Jakus Z, Sitaru C, Simon E, Futosi K, et al. The Src Family Kinases Hck, Fgr, and Lyn Are Critical for the Generation of the In Vivo Inflammatory Environment Without a Direct Role in Leukocyte Recruitment. J Exp Med (2014) 211:1993-2011. doi: 10.1084/jem.20132496

72. Tecchio C, Cassatella MA. Neutrophil-Derived Chemokines on the Road to Immunity. Semin Immunol (2016) 28:119-28. doi: 10.1016/j.smim. 2016.04.003

73. Weber FC, Németh T, Csepregi JZ, Dudeck A, Roers A, Ozsvári B, et al. Neutrophils Are Required for Both the Sensitization and Elicitation Phase of Contact Hypersensitivity. J Exp Med (2015) 212:15-22. doi: 10.1084/ jem.20130062

74. Mantovani A, Cassatella MA, Costantini C, Jaillon S. Neutrophils in the Activation and Regulation of Innate and Adaptive Immunity. Nat Rev Immunol (2011) 11:519-31. doi: 10.1038/nri3024

75. Mócsai A. Diverse Novel Functions of Neutrophils in Immunity, Inflammation, and Beyond. J Exp Med (2013) 210:1283-99. doi: 10.1084/ jem. 20122220

76. Scapini P, Cassatella MA. Social Networking of Human Neutrophils Within the Immune System. Blood (2014) 124:710-9. doi: 10.1182/blood-2014-03453217

77. Timár CI, Lorincz AM, Csépányi-Kömi R, Vályi-Nagy A, Nagy G, Buzás EI, et al. Antibacterial Effect of Microvesicles Released From Human Neutrophilic Granulocytes. Blood (2013) 121:510-8. doi: 10.1182/blood2012-05-431114

78. Majumdar R, Tavakoli Tameh A, Parent CA. Exosomes Mediate LTB4 Release During Neutrophil Chemotaxis. PloS Biol (2016) 14:e1002336. doi: 10.1371/journal.pbio.1002336

79. Benito-Martin A, Di Giannatale A, Ceder S, Peinado H. The New Deal: A Potential Role for Secreted Vesicles in Innate Immunity and Tumor Progression. Front Immunol (2015) 6:66. doi: 10.3389/fimmu.2015.00066

80. Vargas A, Roux-Dalvai F, Droit A, Lavoie JP. Neutrophil-Derived Exosomes: A New Mechanism Contributing to Airway Smooth Muscle Remodeling. Am J Respir Cell Mol Biol (2016) 55:450-61. doi: 10.1165/rcmb.20160033OC

81. Ostrom QT, Gittleman H, Fulop J, Liu M, Blanda R, Kromer C, et al. CBTRUS Statistical Report: Primary Brain and Central Nervous System Tumors Diagnosed in the United States in 2008-2012, Neuro Oncol. Neuro Oncol (2015) 17(Suppl. 4):iv1-iv62. doi: 10.1093/neuonc/nov189

82. Liu R, Page M, Solheim K, Fox S, Chang SM. Quality of Life in Adults With Brain Tumors: Current Knowledge and Future Directions. Neuro Oncol (2009) 11:330-9. doi: 10.1215/15228517-2008-093

83. Hoffman S, Propp JM, McCarthy BJ. Temporal Trends in Incidence of Primary Brain Tumors in the United States, 1985-1999, Neuro Oncol. Neuro Oncol (2006) 8:27-37. doi: 10.1215/S1522851705000323

84. Deltour I, Johansen C, Auvinen A, Feychting M, Klaeboe L, Schüz J. Time Trends in Brain Tumor Incidence Rates in Denmark, Finland, Norway, and Sweden, 1974-2003. J Natl Cancer Inst (2009) 101:1721-4. doi: 10.1093/jnci/ djp415

85. Stupp R, Mason WP, van den Bent MJ, Weller M, Fisher B, Taphoorn MJ, et al. Radiotherapy Plus Concomitant and Adjuvant Temozolomide for Glioblastoma. N Engl J Med (2005) 352:987-96. doi: 10.1056/ NEJMoa043330

86. Ostrom QT, Gittleman H, Truitt G, Boscia A, Kruchko C, Barnholtz-Sloan JS. CBTRUS Statistical Report: Primary Brain and Other Central Nervous System Tumors Diagnosed in the United States in 2011-2015. Neuro Oncol (2018) 20:iv1-86. doi: 10.1093/neuonc/noy131

87. Molinaro AM, Taylor JW, Wiencke JK, Wrensch MR. Genetic and Molecular Epidemiology of Adult Diffuse Glioma. Nat Rev Neurol (2019) 15:405-17. doi: 10.1038/s41582-019-0220-2

88. Nagasawa DT, Chow F, Yew A, Kim W, Cremer N, Yang I. Temozolomide and Other Potential Agents for the Treatment of Glioblastoma Multiforme. Neurosurg Clin N Am (2012) 23:307-22, ix. doi: 10.1016/j.nec.2012.01.007
89. Stupp R, Taillibert S, Kanner A, Read W, Steinberg D, Lhermitte B, et al. Effect of Tumor-Treating Fields Plus Maintenance Temozolomide vs Maintenance Temozolomide Alone on Survival in Patients With Glioblastoma: A Randomized Clinical Trial. JAMA (2017) 318:2306-16. doi: $10.1001 /$ jama.2017.18718

90. Sampson JH, Heimberger AB, Archer GE, Aldape KD, Friedman AH, Friedman HS, et al. Immunologic Escape After Prolonged ProgressionFree Survival With Epidermal Growth Factor Receptor Variant III Peptide Vaccination in Patients With Newly Diagnosed Glioblastoma. J Clin Oncol (2010) 28:4722-9. doi: 10.1200/JCO.2010.28.6963

91. Wheeler CJ, Das A, Liu G, Yu JS, Black KL. Clinical Responsiveness of Glioblastoma Multiforme to Chemotherapy After Vaccination. Clin Cancer Res (2004) 10:5316-26. doi: 10.1158/1078-0432.CCR-04-0497

92. Newcomb EW, Demaria S, Lukyanov Y, Shao Y, Schnee T, Kawashima N, et al. The Combination of Ionizing Radiation and Peripheral Vaccination Produces Long-Term Survival of Mice Bearing Established Invasive GL261 Gliomas. Clin Cancer Res (2006) 12:4730-7. doi: 10.1158/1078-0432.CCR-06-0593

93. Nowak AK, Robinson BW, Lake RA. Synergy Between Chemotherapy and Immunotherapy in the Treatment of Established Murine Solid Tumors. Cancer Res (2003) 63:4490-6.

94. Liu G, Black KL, Yu JS. Sensitization of Malignant Glioma to Chemotherapy Through Dendritic Cell Vaccination. Expert Rev Vaccines (2006) 5:233-47. doi: 10.1586/14760584.5.2.233

95. Patel AP, Tirosh I, Trombetta JJ, Shalek AK, Gillespie SM, Wakimoto H, et al. Single-Cell RNA-Seq Highlights Intratumoral Heterogeneity in Primary Glioblastoma. Science (2014) 344:1396-401. doi: 10.1126/science.1254257

96. Mahlokozera T, Vellimana AK, Li T, Mao DD, Zohny ZS, Kim DH, et al. Biological and Therapeutic Implications of Multisector Sequencing in Newly Diagnosed Glioblastoma. Neuro Oncol (2018) 20:472-83. doi: 10.1093/ neuonc/nox 232

97. Reardon DA, Brandes AA, Omuro A, Mulholland P, Lim M, Wick A, et al. Effect of Nivolumab vs Bevacizumab in Patients With Recurrent Glioblastoma: The CheckMate 143 Phase 3 Randomized Clinical Trial. JAMA Oncol (2020) 6(7):1003-10. doi: 10.1001/jamaoncol.2020.1024

98. Weller M, Butowski N, Tran DD, Recht LD, Lim M, Hirte H, et al. Rindopepimut With Temozolomide for Patients With Newly Diagnosed, EGFRvIII- Expressing Glioblastoma (ACT IV): Results of a Randomized, Double- Blind, International Phase 3 Trial. Lancet Oncol (2017) 18:1373-85. doi: 10.1016/S1470-2045(17)30517-X

99. Hodges TR, Ott M, Xiu J, Gatalica Z, Swensen J, Zhou S, et al. Mutational Burden, Immune Checkpoint Expression, and Mismatch Repair in Glioma: Implications for Immune Checkpoint Immunotherapy. Neuro Oncol (2017) 19:1047-57. doi: 10.1093/neuonc/nox026

100. Zajac AJ, Blattman JN, Murali-Krishna K, Sourdive DJ, Suresh M, Altman JD, et al. Viral Immune Evasion Due to Persistence of Activated T Cells Without Effector Function. J Exp Med (1998) 188:2205-13. doi: 10.1084/ jem.188.12.2205

101. Wherry EJ, Blattman JN, Murali-Krishna K, van der Most R, Ahmed R. Viral Persistence Alters CD8 T-Cell Immunodominance and Tissue Distribution and Results in Distinct Stages of Functional Impairment. J Virol (2003) 77:4911-27. doi: 10.1128/JVI.77.8.4911-4927.2003

102. Woroniecka K, Chongsathidkiet P, Rhodin K, Kemeny H, Dechant C, Farber $\mathrm{SH}$, et al. T-Cell Exhaustion Signatures Vary With Tumor Type and Are Severe in Glioblastoma. Clin Cancer Res (2018) 24:4175-86. doi: 10.1158/ 1078-0432.CCR-17-1846

103. Sugihara AQ, Rolle CE, Lesniak MS. Regulatory T Cells Actively Infiltrate Metastatic Brain Tumors. Int J Oncol (2009) 34:1533-40. doi: 10.3892/ ijo_00000282

104. Soffietti R, Rudā R, Mutani R. Management of Brain Metastases. J Neurol (2002) 249:1357-69. doi: 10.1007/s00415-002-0870-6

105. Wesseling P, von Deimling A, Aipape KD, Louis DN, Ohgaki H, Wiestler OD. Metastatic tumours of the CNS. WHO Classification of Tumours of the Central Nervous System. Lyon: IARC (2007) p. 248-51.

106. Lin X, DeAngelis LM. Treatment of Brain Metastases. J Clin Oncol (2015) 33:3475-84. doi: 10.1200/JCO.2015.60.9503

107. Nussbaum ES, Djalilian HR, Cho KH, Hall WA. Brain Metastases: Histology, Multiplicity, Surgery, and Survival. Cancer (1996) 78:1781-8. doi: 10.1002/ (SICI) 1097-0142(19961015)78:8<1781::AID-CNCR19>3.0.CO;2-U 
108. Black PM, Johnson MD. Surgical Resection for Patients With Solid Brain Metastases: Current Status. J Neurooncol (2004) 69:119-24. doi: 10.1023/B: NEON.0000041875.09048.e7

109. Margolin K, Ernstoff MS, Hamid O, Lawrence D, McDermott D, Puzanov I, et al. Ipilimumab in Patients With Melanoma and Brain Metastases: An Open-Label, Phase 2 Trial. Lancet Oncol (2012) 13:459-65. doi: 10.1016/ S1470-2045(12)70090-6

110. Long GV, Atkinson V, Lo S, Sandhu S, Guminski AD, Brown MP, et al. Combination Nivolumab and Ipilimumab or Nivolumab Alone in Melanoma Brain Metastases: A Multicenter Randomised Phase 2 Study. Lancet Oncol (2018) 19:672-81. doi: 10.1016/S1470-2045(18)30139-6

111. Friebel E, Kapolou K, Unger S, Núñez NG, Utz S, Rushing EJ, et al. SingleCell Mapping of Human Brain Cancer Reveals Tumor-Specific Instruction of Tissue-Invading Leukocytes. Cell (2020) 181(7):1626-42.e20. doi: 10.1016/ j.cell.2020.04.055

112. Klemm F, Maas RR, Bowman RL, Kornete M, Soukup K, Nassiri S, et al. Interrogation of the Microenvironmental Landscape in Brain Tumors Reveals Disease-Specific Alterations of Immune Cells. Cell (2020) 181 (7):1643-60. doi: 10.1016/j.cell.2020.05.007

113. Grivennikov SI, Greten FR, Karin M. Immunity, Inflammation, and Cancer. Cell (2010) 140:883-99. doi: 10.1016/j.cell.2010.01.025

114. O'Callaghan DS, O'Donnell D, O'Connell F, O'Byrne KJ. The Role of Inflammation in the Pathogenesis of non-Small Cell Lung Cancer. J Thorac Oncol (2010) 5:2024-36. doi: 10.1097/JTO.0b013e3181f387e4

115. Aggarwal BB, Vijayalekshmi RV, Sung B. Targeting Inflammatory Pathways for Prevention and Therapy of Cancer: Short-Term Friend, Long-Term Foe. Clin Cancer Res (2009) 15:425-30. doi: 10.1158/10780432.CCR-08-0149

116. Roxburgh CS, McMillan DC. Role of Systemic Inflammatory Response in Predicting Survival in Patients With Primary Operable Cancer. Future Oncol (2010) 6:149-63. doi: 10.2217/fon.09.136

117. Viganó A, Bruera E, Jhangri GS, Newman SC, Fields AL, Suarez-Almazor ME, et al. Clinical Survival Predictors in Patients With Advanced Cancer. Arch Intern Med (2000) 160:861-8. doi: 10.1001/archinte.160.6.861

118. Motomura T, Shirabe K, Mano Y, Muto J, Toshima T, Umemoto Y, et al. Neutrophil-lymphocyte Ratio Reflects Hepatocellular Carcinoma Recurrence After Liver Transplantation via Inflammatory Microenvironment. J Hepatol (2013) 58:58-64. doi: 10.1016/j.jhep.2012.08.017

119. Kantola T, Klintrup K, Väyrynen JP, Vornanen J, Bloigu R, Karhu T, et al. Stage-Dependent Alterations of the Serum Cytokine Pattern in Colorectal Carcinoma. Br J Cancer (2012) 107:1729-36. doi: 10.1038/bjc.2012.456

120. McCourt M, Wang JH, Sookhai S, Redmond HP. Proinflammatory Mediators Stimulate Neutrophil-Directed Angiogenesis. Arch Surg (1999) 134:1325-31, discussion 1331-1322. doi: 10.1001/archsurg.134.12.1325

121. Di Carlo E, Forni G, Musiani P. Neutrophils in the Antitumoral Immune Response. Chem Immunol Allergy (2003) 83:182-203. doi: 10.1159/ 000071561

122. McCourt M, Wang JH, Sookhai S, Redmond HP. Activated Human Neutrophils Release Hepatocyte Growth Factor/Scatter Factor. Eur J Surg Oncol (2001) 27:396-403. doi: 10.1053/ejso.2001.1133

123. Jabłońska E, Kiluk M, Markiewicz W, Piotrowski L, Grabowska Z, Jabłoński J. TNF-Alpha, IL-6 and Their Soluble Receptor Serum Levels and Secretion by Neutrophils in Cancer Patients. Arch Immunol Ther Exp (Warsz) (2001) 49:63-9.

124. Schaider H, Oka M, Bogenrieder T, Nesbit M, Satyamoorthy K, Berking C, et al. Differential Response of Primary and Metastatic Melanomas to Neutrophils Attracted by IL-8. Int J Cancer (2003) 103:335-43. doi: $10.1002 / \mathrm{ijc} .10775$

125. Shamamian P, Schwartz JD, Pocock BJ, Monea S, Whiting D, Marcus SG, et al. Activation of Progelatinase A (MMP-2) by Neutrophil Elastase, Cathepsin G, and Proteinase-3: A Role for Inflammatory Cells in Tumor Invasion and Angiogenesis. J Cell Physiol (2001) 189:197-206. doi: 10.1002/ jcp.10014

126. Scapini P, Nesi L, Morini M, Tanghetti E, Belleri M, Noonan D, et al. Generation of Biologically Active Angiostatin Kringle 1-3 by Activated Human Neutrophils. J Immunol (2002) 168:5798-804. doi: 10.4049/ jimmunol.168.11.5798
127. Agliardi G, Liuzzi AR, Hotblack A, De Feo D, Núñez N, Stowe CL, et al. Intratumoral IL-12 Delivery Empowers CAR-T Cell Immunotherapy in a Pre-Clinical Model of Glioblastoma. Nat Commun (2021) 12(1):444. doi: 10.1038/s41467-020-20599-x

128. McMillan DC. The Systemic Inflammation-Based Glasgow Prognostic Score: A Decade of Experience in Patients With Cancer. Cancer Treat Rev (2013) 39:534-40. doi: 10.1016/j.ctrv.2012.08.003

129. Petrie HT, Klassen LW, Kay HD. Inhibition of Human Cytotoxic T Lymphocyte Activity In Vitro by Autologous Peripheral Blood Granulocytes. J Immunol (1985) 134:230-4.

130. el-Hag A, Clark RA. Immunosuppression by Activated Human Neutrophils. Dependence on the Myeloperoxidase System. J Immunol (1987) 139:2406-13.

131. Loi S, Sirtaine N, Piette F, Salgado R, Viale G, Van Eenoo F, et al. Prognostic and Predictive Value of Tumor-Infiltrating Lymphocytes in a Phase III Randomized Adjuvant Breast Cancer Trial in Node-Positive Breast Cancer Comparing the Addition of Docetaxel to Doxorubicin With DoxorubicinBased Chemotherapy: BIG 02-98. J Clin Oncol (2013) 31:860-7. doi: 10.1200/JCO.2011.41.0902

132. Gooden MJ, de Bock GH, Leffers N, Daemen T, Nijman HW. The Prognostic Influence of Tumour-Infiltrating Lymphocytes in Cancer: A Systematic Review With Meta-Analysis. Br J Cancer (2011) 105:93-103. doi: 10.1038/ bjc.2011.189

133. Denkert C, Loibl S, Noske A, Roller M, Müller BM, Komor M, et al. TumorAssociated Lymphocytes as an Independent Predictor of Response to Neoadjuvant Chemotherapy in Breast Cancer. J Clin Oncol (2010) 28:10513. doi: $10.1200 / J C O .2009 .23 .7370$

134. Guthrie GJ, Charles KA, Roxburgh CS, Horgan PG, McMillan DC, Clarke SJ. The Systemic Inflammation Based Neutrophil-Lymphocyte Ratio: Experience in Patients With Cancer. Crit Rev Oncol Hematol (2013) 88:218-30. doi: 10.1016/j.critrevonc.2013.03.010

135. Kao SC, Pavlakis N, Harvie R, Vardy JL, Boyer MJ, van Zandwijk N, et al. High Blood Neutrophil-to-Lymphocyte Ratio Is an Indicator of Poor Prognosis in Malignant Mesothelioma Patients Undergoing Systemic Therapy. Clin Cancer Res (2010) 16:5805-13. doi: 10.1158/1078-0432. CCR-10-2245

136. Chua W, Charles KA, Baracos VE, Clarke SJ. Neutrophil/lymphocyte Ratio Predicts Chemotherapy Outcomes in Patients With Advanced Colorectal Cancer. Br J Cancer (2011) 104:1288-95. doi: 10.1038/bjc. 2011.100

137. Botta C, Mazzanti R, Guglielmo A, Cusi MG, Vincenzi B, Mantovani G, et al. Treatment-Related Changes in Systemic Inflammatory Status, Measured by Neutrophil-to-Lymphocyte Ratio, Is Predictive of Outcome in Metastatic Colorectal Cancer Patients. Eur J Cancer (2011) 47:S181. doi: 10.1016/S09598049(11)70932-7

138. Lee Y, Kim SH, Han JY, Kim HT, Yun T, Lee JS. Early Neutrophil-toLymphocyte Ratio Reduction as a Surrogate Marker of Prognosis in Never Smokers With Advanced Lung Adenocarcinoma Receiving Gefitinib or Standard Chemotherapy as First-Line Therapy. J Cancer Res Clin Oncol (2012) 138:2009-16. doi: 10.1007/s00432-012-1281-4

139. Leibowitz-Amit R, Templeton AJ, Atenafu EG, Vera-Badillo FE, Chllamma M, Solow HL, et al. Novel Predictive Markers of PSA Response to Abiraterone Acetate in Men With Metastatic Castration-ResistantProstate-Cancer (mCRPC). J Clin Oncol (2013) 31(Suppl.):5058. doi: 10.1200/jco.2013.31.15_suppl.5058

140. Park YH, Lee YJ, Ku JH, Kwak C, Kim HH. Neutrophil-To-Lymphocyte Ratio Reduction as a Surrogate Marker of Prognosis in Patients With Metastatic Clear Cell Renal Cell Carcinoma Receiving Sunitinib as FirstLine Therapy. J Urol (2013) 189:e787. doi: 10.1016/j.juro.2013.02.2338

141. Gabrusiewicz K, Rodriguez B, Wei J, Hashimoto Y, Healy LM, Maiti SN, et al. Glioblastoma-Infiltrated Innate Immune Cells Resemble M0 Macrophage Phenotype. JCI Insight (2016) 1(2):e85841. doi: 10.1172/ jci.insight. 85841

142. Nitta T, Sato K, Allegretta M, Brocke S, Lim M, Mitchell DJ, et al. Expression of Granulocyte Colony Stimulating Factor and Granulocyte-Macrophage Colony Stimulating Factor Genes in Human Astrocytoma Cell Lines and in Glioma Specimens. Brain Res (1992) 571:19-25. doi: 10.1016/0006-8993(92) 90505-4 
143. Albulescu R, Codrici E, Popescu ID, Mihai S, Necula LG, Petrescu D, et al. Cytokine Patterns in Brain Tumour Progression. Mediators Inflamm (2013) 2013:979748. doi: 10.1155/2013/979748

144. Bambury RM, Teo MY, Power DG, Yusuf A, Murray S, Battley JE, et al. The Association of Pre-Treatment Neutrophil to Lymphocyte Ratio With Overall Survival in Patients With Glioblastoma Multiforme. J Neurooncol (2013) 114:149-54. doi: 10.1007/s11060-013-1164-9

145. Wiencke JK, Koestler DC, Salas LA, Wiemels JL, Roy RP, Hansen HM, et al. Immunomethylomic Approach to Explore the Blood Neutrophil Lymphocyte Ratio (NLR) in Glioma Survival. Clin Epigenet (2017) 9:10. doi: 10.1186/s13148-017-0316-8

146. McNamara MG, Lwin Z, Jiang H, Templeton AJ, Zadeh G, Bernstein M, et al. Factors Impacting Survival Following Second Surgery in Patients With Glioblastoma in the Temozolomide Treatment Era, Incorporating Neutrophil/Lymphocyte Ratio and Time to First Progression. J Neurooncol (2014) 117:147-52. doi: 10.1007/s11060-014-1366-9

147. Mason M, Maurice C, McNamara MG, Tieu MT, Lwin Z, Millar BA, et al. Neutrophil-Lymphocyte Ratio Dynamics During Concurrent Chemoradiotherapy for Glioblastoma Is an Independent Predictor for Overall Survival. J Neurooncol (2017) 132:463-71. doi: 10.1007/s11060017-2395-y

148. Wang PF, Song HW, Cai HQ, Kong LW, Yao K, Jiang T, et al. Preoperative Inflammation Markers and IDH Mutation Status Predict Glioblastoma Patient Survival. Oncotarget (2017) 8:50117-23. doi: 10.18632/ oncotarget. 15235

149. Bertaut A, Truntzer C, Madkouri R, Kaderbhai CG, Derangère V, Vincent J, et al. Blood Baseline Neutrophil Count Predicts Bevacizumab Efficacy in Glioblastoma. Oncotarget (2016) 7:70948-58. doi: 10.18632/ oncotarget.10898

150. Rahbar A, Cederarv M, Wolmer-Solberg N, Tammik C, Stragliotto G, Peredo I, et al. Enhanced Neutrophil Activity Is Associated With Shorter Time to Tumor Progression in Glioblastoma Patients. Oncoimmunology (2016) 5: e1075693. doi: 10.1080/2162402X.2015.1075693

151. Sippel TR, White J, Nag K, Tsvankin V, Klaassen M, KleinschmidtDeMasters BK, et al. Neutrophil Degranulation and Immunosuppression in Patients With GBM: Restoration of Cellular Immune Function by Targeting Arginase I. Clin Cancer Res (2011) 17:6992-7002. doi: 10.1158/ 1078-0432.CCR-11-1107

152. Scoccianti S, Ricardi U. Treatment of Brain Metastases: Review of Phase III Randomized Controlled Trials. Radiother Oncol (2012) 102:168-79. doi: 10.1016/j.radonc.2011.08.041

153. Gaspar L, Scott C, Rotman M, Asbell S, Phillips T, Wasserman T, et al. Recursive Partitioning Analysis (RPA) of Prognostic Factors in Three Radiation Therapy Oncology Group (RTOG) Brain Metastases Trials. Int J Radiat Oncol Biol Phys (1997) 37:745-51. doi: 10.1016/S0360-3016(96) 00619-0

154. Sperduto PW, Berkey B, Gaspar LE, Mehta M, Curran W. A New Prognostic Index and Comparison to Three Other Indices for Patients With Brain Metastases: An Analysis of 1,960 Patients in the RTOG Database. Int J Radiat Oncol Biol Phys (2008) 70:510-4. doi: 10.1016/j.ijrobp.2007.06.074

155. Hanahan D, Weinberg RA. The Hallmarks of Cancer. Cell (2000) 100:57-70. doi: 10.1016/S0092-8674(00)81683-9

156. Mitsuya K, Nakasu Y, Kurakane T, Hayashi N, Harada H, Nozaki K. Elevated Preoperative Neutrophil-to-Lymphocyte Ratio as a Predictor of Worse Survival After Resection in Patients With Brain Metastasis. J Neurosurg (2017) 127:433-7. doi: 10.3171/2016.8.JNS16899

157. Zhang L, Hu Y, Chen W, Tian Y, Xie Y, Chen J. Pre-Stereotactic Radiosurgery Neutrophil-to-Lymphocyte Ratio Is a Predictor of the Prognosis for Brain Metastases. J Neurooncol (2020) 147:691-700. doi: 10.1007/s11060-020-03477-w

158. Chowdhary M, Switchenko JM, Press RH, Jhaveri J, Buchwald ZS, Blumenfeld PA, et al. Post-Treatment Neutrophil-to-Lymphocyte Ratio Predicts for Overall Survival in Brain Metastases Treated With Stereotactic Radiosurgery. J Neurooncol (2018) 139:689-97. doi: 10.1007/s11060-018-2914-5

159. Alagappan M, Pollom EL, von Eyben R, Kozak MM, Aggarwal S, Poultsides GA, et al. Albumin and Neutrophil-Lymphocyte Ratio (NLR) Predict Survival in Patients With Pancreatic Adenocarcinoma Treated With SBRT. Am J Clin Oncol (2018) 41:242-7. doi: 10.1097/COC.0000000000000263
160. Hyder J, Boggs DH, Hanna A, Suntharalingam M, Chuong MD. Changes in Neutrophil-to-Lymphocyte and Platelet-Tolymphocyte Ratios During Chemoradiation Predict for Survival and Pathologic Complete Response in Trimodality Esophageal Cancer Patients. J Gastrointest Oncol (2016) 7:18995. doi: 10.3978/j.issn.2078-6891.2015.080

161. Shaverdian N, Veruttipong D, Wang J, Schaue D, Kupelian P, Lee P. Pretreatment Immune Parameters Predict for Overall Survival and Toxicity in Early-Stage Non-Small-Cell Lung Cancer Patients Treated With Stereotactic Body Radiation Therapy. Clin Lung Cancer (2016) 17:39-46. doi: 10.1016/j.cllc.2015.07.007

162. Ulusoy R, Yokuşoğlu M, Kırılmaz A, Nevruz O, Baysan O, Kılıçaslan F. Mean Platelet Volume in ST Elevation and non-ST Elevation Myocardial Infarction. Gulhane Med J (2011) 53(2):114-8.

163. Bhat T, Teli S, Rijal J, Bhat H, Raza M, Khoueiry G, et al. Neutrophil to Lymphocyte Ratio and Cardiovascular Diseases: A Review. Expert Rev Cardiovasc Ther (2013) 11:55-9. doi: 10.1586/erc.12.159

164. Balta S, Demirkol S, Cakar M, Arslan Z, Unlu M, Celik T. Other Inflammatory Markers Should Not be Forgotten When Assessing the Neutrophil-to-Lymphocyte Ratio. Clin Appl Thromb Hemost (2013) 19:693-4. doi: 10.1177/1076029613486019

165. Fridlender ZG, Sun J, Kim S, Kapoor V, Cheng G, Ling L, et al. Polarization of Tumor-Associated Neutrophil Phenotype by TGF- $\beta$ : "N1" Versus "N2" TAN. Cancer Cell (2009) 16:183-94. doi: 10.1016/j.ccr.2009.06.017

166. Granot Z, Fridlender ZG. Plasticity Beyond Cancer Cells and the "Immunosuppressive Switch". Cancer Res (2015) 75:4441-5. doi: 10.1158/ 0008-5472.CAN-15-1502

167. Sionov RV, Fridlender ZG, Granot Z. The Multifaceted Roles Neutrophils Play in the Tumor Microenvironment. Cancer Microenviron (2015) 8:12558. doi: 10.1007/s12307-014-0147-5

168. Andzinski L, Kasnitz N, Stahnke S, Wu CF, Gereke M, von KöckritzBlickwede $\mathrm{M}$, et al. Type I IFNs Induce Anti-Tumor Polarization of Tumor Associated Neutrophils in Mice and Human. Int J Cancer (2016) 138:1982-93. doi: 10.1002/ijc.29945

169. Noy R, Pollard JW. Tumor-Associated Macrophages: From Mechanisms to Therapy. Immunity (2014) 41:49-61. doi: 10.1016/j.immuni.2014.06.010

170. Qian BZ, Pollard JW. Macrophage Diversity Enhances Tumor Progression and Metastasis. Cell (2010) 141:39-51. doi: 10.1016/j.cell.2010.03.014

171. Ruffell B, Affara NI, Coussens LM. Differential Macrophage Programming in the Tumor Microenvironment. Trends Immunol (2012) 33:119-26. doi: 10.1016/j.it.2011.12.001

172. Brandau S, Trellakis S, Bruderek K, Schmaltz D, Steller G, Elian M, et al. Myeloid-Derived Suppressor Cells in the Peripheral Blood of Cancer Patients Contain a Subset of Immature Neutrophils With Impaired Migratory Properties. J Leukoc Biol (2011) 89:311-7. doi: 10.1189/jlb.0310162

173. Sagiv JY, Michaeli J, Assi S, Mishalian I, Kisos H, Levy L, et al. Phenotypic Diversity and Plasticity in Circulating Neutrophil Subpopulations in Cancer. Cell Rep (2015) 10:562-73. doi: 10.1016/j.celrep.2014.12.039

174. Lang S, Bruderek K, Kaspar C, Höing B, Kanaan O, Dominas N, et al. Clinical Relevance and Suppressive Capacity of Human Myeloid-Derived Suppressor Cell Subsets. Clin Cancer Res (2018) 24:4834-44. doi: 10.1158/10780432.CCR-17-3726

175. Ley K, Hoffman HM, Kubes P, Cassatella MA, Zychlinsky A, Hedrick CC, et al. Neutrophils: New Insights and Open Questions. Sci Immunol (2018) 3: eaat4579. doi: 10.1126/sciimmunol.aat4579

176. Blaisdell A, Crequer A, Columbus D, Daikoku T, Mittal K, Dey SK, et al. Neutrophils Oppose Uterine Epithelial Carcinogenesis via Debridement of Hypoxic Tumor Cells. Cancer Cell (2015) 28:785-99. doi: 10.1016/ j.ccell.2015.11.005

177. Eruslanov EB, Bhojnagarwala PS, Quatromoni JG, Stephen TL, Ranganathan A, Deshpande C, et al. Tumor-Associated Neutrophils Stimulate T Cell Responses in Early-Stage Human Lung Cancer. J Clin Invest (2014) 124:5466-80. doi: 10.1172/JCI77053

178. Singhal S, Bhojnagarwala PS, O'Brien S, Moon EK, Garfall AL, Rao AS, Quatromoni JG, et al. Origin and Role of a Subset of Tumor-Associated Neutrophils With Antigen-Presenting Cell Features in Early-Stage Human Lung Cancer. Cancer Cell (2016) 30:120-35. doi: 10.1016/j.ccell.2016.06.001

179. Ponzetta A, Carriero R, Carnevale S, Barbagallo M, Molgora M, Perucchini C, et al. Neutrophils Driving Unconventional T Cells Mediate Resistance 
Against Murine Sarcomas and Selected Human Tumors. Cell (2019) 178:346-360.e24. doi: 10.1016/j.cell.2019.05.047

180. Fridlender ZG, Sun J, Mishalian I, Singhal S, Cheng G, Kapoor V, et al. Transcriptomic Analysis Comparing Tumor-Associated Neutrophils With Granulocytic Myeloid-Derived Suppressor Cells and Normal Neutrophils. PloS One (2012) 7:e31524. doi: 10.1371/journal.pone.0031524

181. Mahiddine K, Blaisdell A, Ma S, Créquer-Grandhomme A, Lowell CA, Erlebacher A. Relief of Tumor Hypoxia Unleashes the Tumoricidal Potential of Neutrophils. J Clin Invest (2020) 130:389-403. doi: 10.1172/JCI130952

182. Finisguerra V, Di Conza G, Di Matteo M, Serneels J, Costa S, Thompson AA, et al. MET Is Required for the Recruitment of Anti-Tumoural Neutrophils. Nature (2015) 522:349-53. doi: 10.1038/nature14407

183. Zhu YP, Padgett L, Dinh HQ, Marcovecchio P, Blatchley A, Wu R, et al. Identification of an Early Unipotent Neutrophil Progenitor With ProTumoral Activity in Mouse and Human Bone Marrow. Cell Rep (2018) 24:2329-41.e8. doi: 10.1016/j.celrep.2018.07.097

184. Gupta AK, Joshi MB, Philippova M, Erne P, Hasler P, Hahn S, et al. Activated Endothelial Cells Induce Neutrophil Extracellular Traps and Are Susceptible to NETosis-Mediated Cell Death. FEBS Lett (2010) 584:3193-7. doi: 10.1016/j.febslet.2010.06.006

185. Saffarzadeh M, Juenemann C, Queisser MA, Lochnit G, Barreto G, Galuska SP, et al. Neutrophil Extracellular Traps Directly Induce Epithelial and Endothelial Cell Death: A Predominant Role of Histones. Plos One (2012) 7: e32366. doi: 10.1371/journal.pone.0032366

186. Demers M, Krause DS, Schatzberg D, Martinod K, Voorhees JR, Fuchs TA, et al. Cancers Predispose Neutrophils to Release Extracellular DNA Traps That Contribute to Cancer-Associated Thrombosis. Proc Natl Acad Sci USA (2012) 109:13076-81. doi: 10.1073/pnas.1200419109

187. Tohme S, Yazdani HO, Al-Khafaji AB, Chidi AP, Loughran P, Mowen K, et al. Neutrophil Extracellular Traps Promote the Development and Progression of Liver Metastases After Surgical Stress. Cancer Res (2016) 76:1367-80. doi: 10.1158/0008-5472.CAN-15-1591

188. Richardson JJR, Hendrickse C, Gao-Smith F, Thickett DR. Neutrophil Extracellular Trap Production in Patients With Colorectal Cancer In Vitro. Int J Inflam (2017) 2017:4915062. doi: 10.1155/2017/4915062

189. Albrengues J, Shields MA, Ng D, Park CG, Ambrico A, Poindexter ME, et al. Neutrophil Extracellular Traps Produced During Inflammation Awaken Dormant Cancer Cells in Mice. Science (2018) 361(6409):eaao4227. doi: 10.1126/science.aao4227

190. Graeber MB, Scheithauer BW, Kreutzberg GW. Microglia in Brain Tumors. Glia (2002) 40:252-9. doi: 10.1002/glia.10147

191. Fossati G, Ricevuti G, Edwards SW, Walker C, Dalton A, Rossi ML. Neutrophil Infiltration Into Human Gliomas. Acta Neuropathol (1999) 98:349-54. doi: 10.1007/s004010051093

192. Liang J, Piao Y, Holmes L, Fuller GN, Henry V, Tiao N, et al. Neutrophils Promote the Malignant Glioma Phenotype Through S100A4. Clin Cancer Res (2014) 20:187-98. doi: 10.1158/1078-0432.CCR-13-1279

193. Bresnick AR, Weber DJ, Zimmer DB. S100 Proteins in Cancer. Nat Rev Cancer (2015) 15:96-109. doi: 10.1038/nrc3893

194. Liu Y, Kosaka A, Ikeura M, Kohanbash G, Fellows-Mayle W, Snyder LA, et al. Premetastatic Soil and Prevention of Breast Cancer Brain Metastasis. Neuro Oncol (2013) 15:891-903. doi: 10.1093/neuonc/not031

195. Shaul ME, Fridlender ZG. Neutrophils as Active Regulators of the Immune System in the Tumor Microenvironment. J Leukoc Biol (2017) 102:343-9. doi: 10.1189/jlb.5MR1216-508R

196. Piccard H, Muschel RJ, Opdenakker G. On the Dual Roles and Polarized Phenotypes of Neutrophils in Tumor Development and Progression. Crit Rev Oncol Hematol (2012) 82:296-309. doi: 10.1016/ j.critrevonc.2011.06.004

197. Kim J, Bae JS. Tumor-Associated Macrophages and Neutrophils in Tumor Microenvironment. Mediators Inflammation (2016) 2016:6058147. doi: $10.1155 / 2016 / 6058147$

198. He G, Zhang H, Zhou J, Wang B, Chen Y, Kong Y, et al. Peritumoural Neutrophils Negatively Regulate Adaptive Immunity via the PD-L1/PD-1 Signalling Pathway in Hepatocellular Carcinoma. J Exp Clin Cancer Res (2015) 34:141. doi: 10.1186/s13046-015-0256-0

199. Wang TT, Zhao YL, Peng LS, Chen N, Chen W, Lv YP, et al. TumourActivated Neutrophils in Gastric Cancer Foster Immune Suppression and
Disease Progression Through GM-CSF-PD-L1 Pathway. Gut (2017) 66:1900-11. doi: 10.1136/gutjnl-2016-313075

200. Vols S, Sionov RV, Granot Z. Always Look on the Bright Side: Anti-Tumor Functions of Neutrophils. Curr Pharm Des (2017) 23:4862-92. doi: 10.2174/ 1381612823666170704125420

201. Gregory AD, Houghton AM. Tumor-Associated Neutrophils: New Targets for Cancer Therapy. Cancer Res (2011) 71:2411-6. doi: 10.1158/00085472.CAN-10-2583

202. Ring NG, Herndler-Brandstetter D, Weiskopf K, Shan L, Volkmer JP, George BM, et al. Anti-Sirpo Antibody Immunotherapy Enhances Neutrophil and Macrophage Antitumor Activity. Proc Natl Acad Sci USA (2017) 114: E10578-85. doi: 10.1073/pnas.1710877114

203. Liu Y, Bühring HJ, Zen K, Burst SL, Schnell FJ, Williams IR, et al. Signal Regulatory Protein $(\operatorname{Sirp} \alpha)$, a Cellular Ligand for CD47, Regulates Neutrophil Transmigration. J Biol Chem (2002) 277:10028-36. doi: 10.1074/jbc.M109720200

204. Condamine T, Kumar V, Ramachandran IR, Youn JI, Celis E, Finnberg N, et al. ER Stress Regulates Myeloid-Derived Suppressor Cell Fate Through TRAILR-Mediated Apoptosis. J Clin Invest (2014) 124:2626-39. doi: 10.1172/JCI74056

205. Renshaw SA, Parmar JS, Singleton V, Rowe SJ, Dockrell DH, Dower SK, et al. Acceleration of Human Neutrophil Apoptosis by TRAIL. J Immunol (2003) 170:1027-33. doi: 10.4049/jimmunol.170.2.1027

206. Massara M, Bonavita O, Savino B, Caronni N, Mollica Poeta V, Sironi M, et al. ACKR2 in Hematopoietic Precursors as a Checkpoint of Neutrophil Release and Antimetastatic Activity. Nat Commun (2018) 9:676. doi: 10.1038/s41467-018-03080-8

207. Steele CW, Karim SA, Leach JDG, Bailey P, Upstill-Goddard R, Rishi L, et al. CXCR2 Inhibition Profoundly Suppresses Metastases and Augments Immunotherapy in Pancreatic Ductal Adenocarcinoma. Cancer Cell (2016) 29:832-45. doi: 10.1016/j.ccell.2016.04.014

208. Highfill SL, Cui Y, Giles AJ, Smith JP, Zhang H, Morse E, et al. Disruption of CXCR2-Mediated MDSC Tumor Trafficking Enhances Anti-PD1 Efficacy. Sci Transl Med (2014) 6:237ra67. doi: 10.1126/scitranslmed.3007974

209. Velasco-Velázquez M, Jiao X, De La Fuente M, Pestell TG, Ertel A, et al. CCR5 Antagonist Blocks Metastasis of Basal Breast Cancer Cells. Cancer Res (2012) 72:3839-50. doi: 10.1158/0008-5472.CAN-11-3917

210. Hawila E, Razon H, Wildbaum G, Blattner C, Sapir Y, Shaked Y, et al. CCR5 Directs the Mobilization of CD11b+Gr1+Ly6Clow Polymorphonuclear Myeloid Cells From the Bone Marrow to the Blood to Support Tumor Development. Cell Rep (2017) 21:2212-22. doi: 10.1016/j.celrep.2017.10.104

211. Sung L, Nathan PC, Alibhai SM, Tomlinson GA, Beyene J. Meta-Analysis: Effect of Prophylactic Hematopoietic Colony-Stimulating Factors on Mortality and Outcomes of Infection. Ann Intern Med (2007) 147:400-11. doi: 10.7326/0003-4819-147-6-200709180-00010

212. Lyman GH, Kuderer NM, Crawford J, Wolff DA, Culakova E, Poniewierski MS, et al. Predicting Individual Risk of Neutropenic Complications in Patients Receiving Cancer Chemotherapy. Cancer (2011) 117:1917-27. doi: $10.1002 /$ cncr. 25691

213. Weber R, Fleming V, Hu X, Nagibin V, Groth C, Altevogt P, et al. MyeloidDerived Suppressor Cells Hinder the Anti-Cancer Activity of Immune Checkpoint Inhibitors. Front Immunol (2018) 9:1310. doi: 10.3389/ fimmu.2018.01310

214. Crawford J, Dale DC, Lyman GH. Chemotherapy-Induced Neutropenia: Risks, Consequences, and New Directions for its Management. Cancer (2004) 100:228-37. doi: 10.1002/cncr.11882

215. Mehta HM, Malandra M, Corey SJ. G-CSF and GM-CSF in Neutropenia. J Immunol (2015) 195:1341-9. doi: 10.4049/jimmunol.1500861

216. Spiekermann K, Roesler J, Emmendoerffer A, Elsner J, Welte K. Functional Features of Neutrophils Induced by G-CSF and GM-CSF Treatment: Differential Effects and Clinical Implications. Leukemia (1997) 11:466-78. doi: $10.1038 /$ sj.leu. 2400607

217. Azzarà A, Carulli G, Rizzuti-Gullaci A, Capochiani E, Petrini M. Lenograstim and Filgrastim Effects on Neutrophil Motility in Patients Undergoing Chemotherapy: Evaluation by Computer-Assisted Image Analysis. Am J Hematol (2001) 66:306-7. doi: 10.1002/ajh.1064

218. Berdel WE, Danhauser-Riedl S, Steinhauser G, Winton EF. Various Human Hematopoietic Growth Factors (Interleukin-3, GM-CSF, G-CSF) Stimulate 
Clonal Growth of Nonhematopoietic Tumor Cells. Blood (1989) 73:80-3. doi: 10.1182/blood.V73.1.80.bloodjournal73180

219. Yamashita Y, Nara N, Aoki N. Antiproliferative and Differentiative Effect of Granulocyte-Macrophage Colony-Stimulating Factor on a Variant Human Small Cell Lung Cancer Cell Line. Cancer Res (1989) 49:5334-8.

220. Mach N, Gillessen S, Wilson SB, Sheehan C, Mihm M, Dranoff G. Differences in Dendritic Cells Stimulated In Vivo by Tumors Engineered to Secrete Granulocyte-Macrophage Colony-Stimulating Factor or Flt3-Ligand. Cancer Res (2000) 60:3239-46.

221. Gillessen S, Naumov YN, Nieuwenhuis EE, Exley MA, Lee FS, Mach N, et al. CD1d-Restricted T Cells Regulate Dendritic Cell Function and Antitumor Immunity in a Granulocyte-Macrophage Colony-Stimulating FactorDependent Fashion. Proc Natl Acad Sci USA (2003) 100:8874-9. doi: 10.1073/pnas. 1033098100

222. Gutschalk CM, Herold-Mende CC, Fusenig NE, Mueller MM. Granulocyte Colony-Stimulating Factor and Granulocyte-Macrophage ColonyStimulating Factor Promote Malignant Growth of Cells From Head and Neck Squamous Cell Carcinomas In Vivo. Cancer Res (2006) 66:8026-36. doi: 10.1158/0008-5472.CAN-06-0158

223. Roilides E, Walsh TJ, Pizzo PA, Rubin M. Granulocyte Colony-Stimulating Factor Enhances the Phagocytic and Bactericidal Activity of Normal and Defective Human Neutrophils. J Infect Dis (1991) 163:579-83. doi: 10.1093/ infdis/163.3.579

224. Kitagawa S, Yuo A, Souza LM, Saito M, Miura Y, Takaku F. Recombinant Human Granulocyte Colony-Stimulating Factor Enhances Superoxide Release in Human Granulocytes Stimulated by the Chemotactic Peptide. Biochem Biophys Res Commun (1987) 144:1143-6. doi: 10.1016/0006-291X (87) $91430-6$

225. Demaria S, Formenti SC. Radiation as an Immunological Adjuvant: Current Evidence on Dose and Fractionation. Front Oncol (2012) 2:153. doi: 10.3389/ fonc. 2012.00153

226. Demaria S, Formenti SC. Role of T Lymphocytes in Tumor Response to Radiotherapy. Front Oncol (2012) 2:95. doi: 10.3389/fonc.2012.00095

227. Golden EB, Frances D, Pellicciotta I, Demaria S, Helen Barcellos-Hoff M, Formenti SC. Radiation Fosters Dose-Dependent and ChemotherapyInduced Immunogenic Cell Death. Oncoimmunology (2014) 3:e28518. doi: 10.4161/onci.28518

228. Takeshima T, Pop LM, Laine A, Iyengar P, Vitetta ES, Hannan R. Key Role for Neutrophils in Radiation-Induced Antitumor Immune Responses: Potentiation With G-CSF. Proc Natl Acad Sci USA (2016) 113:11300-5. doi: 10.1073 /pnas.1613187113

229. Schernberg A, Blanchard P, Chargari C, Deutsch E. Neutrophils, a Candidate Biomarker and Target for Radiation Therapy? Acta Oncol (2017) 56:152230. doi: 10.1080/0284186X.2017.1348623

230. Bahig H, Taussky D, Delouya G, Nadiri A, Gagnon-Jacques A, BodsonClermont P, et al. Neutrophil Count Is Associated With Survival in Localized Prostate Cancer. BMC Cancer (2015) 15:594. doi: 10.1186/s12885-015-1599-9

231. Escande A, Haie-Meder C, Maroun P, Gouy S, Mazeron R, Leroy T, et al. Neutrophilia in Locally Advanced Cervical Cancer: A Novel Biomarker for Image-Guided Adaptive Brachytherapy? Oncotarget (2016) 7:74886-94. doi: 10.18632/oncotarget. 12440

232. Schernberg A, Moureau-Zabotto L, Rivin Del Campo E, Escande A, Ducreux M, Nguyen F, Goere D, et al. Leukocytosis and Neutrophilia Predict Outcome in Locally Advanced Esophageal Cancer Treated With Definitive Chemoradiation. Oncotarget (2017) 8:11579-88. doi: 10.18632/ oncotarget. 14584

233. Teitz-Tennenbaum S, Li Q, Rynkiewicz S, Ito F, Davis MA, McGinn CJ, et al. Radiotherapy Potentiates the Therapeutic Efficacy of Intratumoral Dendritic Cell Administration. Cancer Res (2003) 63:8466-75.

234. Demaria S, Ng B, Devitt ML, Babb JS, Kawashima N, Liebes L, et al. Ionizing Radiation Inhibition of Distant Untreated Tumors (Abscopal Effect) Is Immune Mediated. Int J Radiat Oncol Biol Phys (2004) 58:862-70. doi: 10.1016/j.ijrobp.2003.09.012

235. Finkelstein SE, Iclozan C, Bui MM, Cotter MJ, Ramakrishnan R, Ahmed J, et al. Combination of External Beam Radiotherapy (EBRT) With Intratumoral Injection of Dendritic Cells as Neo-Adjuvant Treatment of High-Risk Soft Tissue Sarcoma Patients. Int J Radiat Oncol Biol Phys (2012) 82:924-32. doi: 10.1016/j.ijrobp.2010.12.068
236. Golden EB, Chhabra A, Chachoua A, Adams S, Donach M, Fenton-Kerimian $\mathrm{M}$, et al. Local Radiotherapy and Granulocyte-Macrophage ColonyStimulating Factor to Generate Abscopal Responses in Patients With Metastatic Solid Tumours: A Proof-of-Principle Trial. Lancet Oncol (2015) 16:795-803. doi: 10.1016/S1470-2045(15)00054-6

237. Hiniker SM, Chen DS, Reddy S, Chang DT, Jones JC, Mollick JA, et al. A Systemic Complete Response of Metastatic Melanoma to Local Radiation and Immunotherapy. Transl Oncol (2012) 5:404-7. doi: 10.1593/tlo.12280

238. Golden EB, Demaria S, Schiff PB, Chachoua A, Formenti SC. An Abscopal Response to Radiation and Ipilimumab in a Patient With Metastatic NonSmall Cell Lung Cancer. Cancer Immunol Res (2013) 1:365-72. doi: 10.1158/ 2326-6066.CIR-13-0115

239. Demaria S, Golden EB, Formenti SC. Role of Local Radiation Therapy in Cancer Immunotherapy. JAMA Oncol (2015) 1:1325-32. doi: 10.1001/ jamaoncol.2015.2756

240. Liu X, Cho WC. Precision Medicine in Immune Checkpoint Blockade Therapy for non-Small Cell Lung Cancer. Clin Transl Med (2017) 6:7. doi: 10.1186/s40169-017-0136-7

241. Remon J, Besse B. Immune Checkpoint Inhibitors in First-Line Therapy of Advanced Non-Small Cell Lung Cancer. Curr Opin Oncol (2017) 29:97-104. doi: 10.1097/CCO.0000000000000351

242. Gubin MM, Esaulova E, Ward JP, Malkova ON, Runci D, Wong P, et al. High-Dimensional Analysis Delineates Myeloid and Lymphoid Compartment Remodeling During Successful Immune-Checkpoint Cancer Therapy. Cell (2018) 175:1014-30.e19. doi: 10.1016/j.cell.2018.09.030

243. Riaz N, Havel JJ, Makarov V, Desrichard A, Urba WJ, Sims JS, et al. Tumor and Microenvironment Evolution During Immunotherapy With Nivolumab. Cell (2017) 171:934-49.e16. doi: 10.1016/j.cell.2017.09.028

244. Krieg C, Nowicka M, Guglietta S, Schindler S, Hartmann FJ, Weber LM, et al. High-Dimensional Single-Cell Analysis Predicts Response to Anti-PD-1 Immunotherapy. Nat Med (2018) 24:144-53. doi: 10.1038/nm.4466

245. Madonna G, Ballesteros-Merino C, Feng Z, Bifulco C, Capone M, Giannarelli D, et al. PD-L1 Expression With Immune-Infiltrate Evaluation and Outcome Prediction in Melanoma Patients Treated With Ipilimumab. Oncoimmunology (2018) 7:e1405206. doi: 10.1080/2162402X.2017.1405206

246. Apel F, Zychlinsky A, Kenny EF. The Role of Neutrophil Extracellular Traps in Rheumatic Diseases. Nat Rev Rheumatol (2018) 14:467-75. doi: 10.1038/ s41584-018-0039-z

247. Papayannopoulos V, Metzler KD, Hakkim A, Zychlinsky A. Neutrophil Elastase and Myeloperoxidase Regulate the Formation of Neutrophil Extracellular Traps. J Cell Biol (2010) 191:677-91. doi: 10.1083/ jcb. 201006052

248. Bronze-da-Rocha E, Santos-Silva A. Neutrophil Elastase Inhibitors and Chronic Kidney Disease. Int J Biol Sci (2018) 14:1343-60. doi: 10.7150/ ijbs. 26111

249. Stockley R, De Soyza A, Gunawardena K, Perrett J, Forsman-Semb K, Entwistle N, et al. Phase II Study of a Neutrophil Elastase Inhibitor (AZD9668) in Patients With Bronchiectasis. Respir Med (2013) 107:52433. doi: 10.1016/j.rmed.2012.12.009

250. Li P, Li M, Lindberg MR, Kennett MJ, Xiong N, Wang Y. PAD4 Is Essential for Antibacterial Innate Immunity Mediated by Neutrophil Extracellular Traps. J Exp Med (2010) 207:1853-62. doi: 10.1084/jem.20100239

251. Lewis HD, Liddle J, Coote JE, Atkinson SJ, Barker MD, Bax BD, et al. Inhibition of PAD4 Activity Is Sufficient to Disrupt Mouse and Human NET Formation. Nat Chem Biol (2015) 11:189-91. doi: 10.1038/nchembio.1735

252. Koushik S, Joshi N, Nagaraju S, Mahmood S, Mudeenahally K, Padmavathy R, et al. PAD4: Pathophysiology, Current Therapeutics and Future Perspective in Rheumatoid Arthritis. Expert Opin Ther Targets (2017) 21:433-47. doi: 10.1080/14728222.2017.1294160

253. Brill A, Fuchs TA, Savchenko AS, Thomas GM, Martinod K, De Meyer SF, et al. Neutrophil Extracellular Traps Promote Deep Vein Thrombosis in Mice. J Thromb Haemost (2012) 10:136-44. doi: 10.1111/j.1538-7836.2011.04544.x

254. Caudrillier A, Kessenbrock K, Gilliss BM, Nguyen JX, Marques MB, Monestier $\mathrm{M}$, et al. Platelets Induce Neutrophil Extracellular Traps in Transfusion-Related Acute Lung Injury. J Clin Invest (2012) 122:2661-71. doi: 10.1172/JCI61303

255. Thomas GM, Carbo C, Curtis BR, Martinod K, Mazo IB, Schatzberg D, et al. Extracellular DNA Traps Are Associated With the Pathogenesis of TRALI in 
Humans and Mice. Blood (2012) 119:6335-43. doi: 10.1182/blood-2012-01405183

256. Cools-Lartigue J, Spicer J, McDonald B, Gowing S, Chow S, Giannias B, et al. Neutrophil Extracellular Traps Sequester Circulating Tumor Cells and Promote Metastasis. J Clin Invest (2013) 123:3446-58. doi: 10.1172/ JCI67484

257. Park JK, Hodges T, Arko L, Shen M, Dello Iacono D, McNabb A, et al. Scale to Predict Survival After Surgery for Recurrent Glioblastoma Multiforme. J Clin Oncol (2010) 28:3838-43. doi: 10.1200/JCO.2010.30.0582

258. Lacroix M, Abi-Said D, Fourney DR, Gokaslan ZL, Shi W, DeMonte F, et al. A Multivariate Analysis of 416 Patients With Glioblastoma Multiforme: Prognosis, Extent of Resection, and Survival. J Neurosurg (2001) 95:190-8. doi: $10.3171 /$ jns.2001.95.2.0190

259. Groothuis DR. The Blood-Brain and Blood-Tumor Barriers: A Review of Strategies for Increasing Drug Delivery. Neuro Oncol (2000) 2:45-59. doi: 10.1215/15228517-2-1-45

260. Neuwelt EA, Bauer B, Fahlke C, Fricker G, Iadecola C, Janigro D, et al. Engaging Neuroscience to Advance Translational Research in Brain Barrier Biology. Nat Rev Neurosci (2011) 12:169-82. doi: 10.1038/nrn2995

261. Amoretti M, Amsler C, Bonomi G, Bouchta A, Bowe P, Carraro C, et al. Production and Detection of Cold Antihydrogen Atoms. Nature (2002) 419:456-9. doi: 10.1038/nature01096

262. Peer D, Karp JM, Hong S, Farokhzad OC, Margalit R, Langer R. Nanocarriers as an Emerging Platform for Cancer Therapy. Nat Nanotechnol (2007) 2:751-60. doi: $10.1038 /$ nnano.2007.387

263. Mo R, Gu Z. Tumor Microenvironment and Intracellular Signal-Activated Nanomaterials for Anticancer Drug Delivery. Mater Today (2016) 19:27483. doi: 10.1016/j.mattod.2015.11.025

264. Lu Y, Aimetti AA, Langer R, Gu Z. Bioresponsive Materials. Nat Mater Rev (2016) 1:16075. doi: 10.1038/natrevmats.2016.75

265. Mangraviti A, Gullotti D, Tyler B, Brem H. Nanobiotechnology-Based Delivery Strategies: New Frontiers in Brain Tumor Targeted Therapies. J Control Release (2016) 240:443-53. doi: 10.1016/j.jconrel.2016.03.031

266. Cheng Y, Morshed RA, Auffinger B, Tobias AL, Lesniak MS. Multifunctional Nanoparticles for Brain Tumor Imaging and Therapy. Adv Drug Deliv Rev (2014) 66:42-57. doi: 10.1016/j.addr.2013.09.006

267. Lee C, Hwang HS, Lee S, Kim B, Kim JO, Oh KT, et al. Rabies Virus-Inspired Silica-Coated Gold Nanorods as a Photothermal Therapeutic Platform for Treating Brain Tumors. Adv Mater (2017) 29:28134459. doi: 10.1002/ adma.201605563

268. Singh A, Kim W, Kim Y, Jeong K, Kang CS, Kim Y, et al. Multifunctional Photonics Nanoparticles for Crossing the Blood-Brain Barrier and Effecting Optically Trackable Brain Theranostics. Adv Funct Mater (2016) 26:705766. doi: 10.1002/adfm.201602808

269. Zeng L, Zou L, Yu H, He X, Cao H, Zhan Z, et al. Treatment of Malignant Brain Tumor by Tumor-Triggered Programmed Wormlike Micelles With Precise Targeting and Deep Penetration. Adv Funct Mater (2016) 26:420112. doi: $10.1002 /$ adfm. 201600642

270. Zhang X, Yao S, Liu C, Jiang Y. Tumor Tropic Delivery of DoxorubicinPolymer Conjugates Using Mesenchymal Stem Cells for Glioma Therapy. Biomaterials (2015) 39:269-81. doi: 10.1016/j.biomaterials.2014.11.003

271. Roger M, Clavreul A, Venier-Julienne MC, Passirani C, Sindji L, Schiller P, et al. Mesenchymal Stem Cells as Cellular Vehicles for Delivery of Nanoparticles to Brain Tumors. Biomaterials (2010) 31:8393-401. doi: 10.1016/j.biomaterials.2010.07.048

272. Bexell D, Scheding S, Bengzon J. Toward Brain Tumor Gene Therapy Using Multipotent Mesenchymal Stromal Cell Vectors. Mol Ther (2010) 18:106775. doi: $10.1038 / \mathrm{mt} .2010 .58$

273. Roger M, Clavreul A, Huynh NT, Passirani C, Schiller P, Vessiéres A, et al. Ferrociphenol Lipid Nanocapsule Delivery by Mesenchymal Stromal Cells in Brain Tumor Therapy. Int J Pharm (2012) 423:63-8. doi: 10.1016/ j.ijpharm.2011.04.058

274. Kim SM, Lim JY, Park SI, Jeong CH, Oh JH, Jeong M, et al. Gene Therapy Using TRAIL-Secreting Human Umbilical Cord Blood-Derived Mesenchymal Stem Cells Against Intracranial Glioma. Cancer Res (2008) 68:9614-23. doi: 10.1158/0008-5472.CAN-08-0451

275. Pierigè F, Serafini S, Rossi L, Magnani M. Cell-Based Drug Delivery. $A d v$ Drug Deliv Rev (2008) 60(2):286-95. doi: 10.1016/j.addr.2007.08.029
276. Batrakova EV, Gendelman HE, Kabanov AV. Cell-Mediated Drug Delivery. Expert Opin Drug Deliv (2011) 8:415-33. doi: 10.1517/17425247.2011.559457

277. Gu L, Mooney DJ. Biomaterials and Emerging Anticancer Therapeutics: Engineering the Microenvironment. Nat Rev Cancer (2016) 16:56-66. doi: 10.1038/nrc.2015.3

278. Kolaczkowska E, Kubes P. Neutrophil Recruitment and Function in Health and Inflammation. Nat Rev Immunol (2013) 13:159-75. doi: 10.1038/nri3399

279. Phillipson M, Kubes P. The Neutrophil in Vascular Inflammation. Nat Med (2011) 17:1381-90. doi: 10.1038/nm.2514

280. Nathan C. Neutrophils and Immunity: Challenges and Opportunities. Nat Rev Immunol (2006) 6:173-82. doi: 10.1038/nri1785

281. Inglis VI, Jones MPJ, Tse ADY, Easton AS. Neutrophils Both Reduce and Increase Permeability in a Cell Culture Model of the Blood-Brain Barrier. Brain Res (2004) 998:218-29. doi: 10.1016/j.brainres.2003.11.031

282. Bernardes-Silva M, Anthony DC, Issekutz AC, Perry VH. Recruitment of Neutrophils Across the Blood-Brain Barrier: The Role of E- and P-Selectins. J Cereb Blood Flow Metab (2001) 21:1115-24. doi: 10.1097/00004647200109000-00009

283. Uehara T, Baba I, Nomura Y. Induction of Cytokine-Induced Neutrophil Chemoattractant in Response to Various Stresses in Rat C6 Glioma Cells. Brain Res (1998) 790:284-92. doi: 10.1016/S0006-8993(98)00080-8

284. Mishalian I, Bayuh R, Levy L, Zolotarov L, Michaeli J, Fridlender ZG, et al. Tumor-Associated Neutrophils (TAN) Develop Pro-Tumorigenic Properties During Tumor Progression. Cancer Immunol Immunother (2013) 62:174556. doi: 10.1007/s00262-013-1476-9

285. Salmaggi A, Eoli M, Frigerio S, Silvani A, Gelati M, Corsini E, et al. Intracavitary vEGF, bFGF, IL-8, IL-12 Levels in Primary and Recurrent Malignant Glioma. J Neurooncol (2003) 62:297-303. doi: 10.1023/ a:1023367223575

286. Brat DJ, Bellail AC, VanMeir EG. The Role of Interleukin-8 and Its Receptors in Gliomagenesis and Tumoral Angiogenesis. Neuro Oncol (2005) 7:122-33. doi: 10.1215/S1152851704001061

287. Ryuto M, Ono M, Izumi H, Yoshida S, Weich HA, Kohno K, et al. Induction of Vascular Endothelial Growth Factor by Tumor Necrosis Factor Alpha in Human Glioma Cells. Possible Roles SP-1 J Biol Chem (1996) Nov 8271 (45):28220-8. doi: 10.1074/jbc.271.45.28220

288. Nabors LB, Suswam E, Huang Y, Yang X, Johnson MJ, King PH. Tumor Necrosis Factor $\alpha$ Induces Angiogenic Factor Up-Regulation in Malignant Glioma Cells: A Role for RNA Stabilization and HuR. Cancer Res (2003) 63:4181-7.

289. Xue J, Zhao Z, Zhang L, Xue L, Shen S, Wen Y, et al. Neutrophil-Mediated Anticancer Drug Delivery for Suppression of Postoperative Malignant Glioma Recurrence. Nat Nanotechnol (2017) 12:692-700. doi: 10.1038/ nnano.2017.54

290. Iyer AK, Khaled G, Fang J, Maeda H. Exploiting the Enhanced Permeability and Retention Effect for Tumor Targeting. Drug Discov Today (2006) 11:812-8. doi: 10.1016/j.drudis.2006.07.005

291. Bertrand N, Wu J, Xu X, Kamaly N, Farokhzad OC. Cancer Nanotechnology: The Impact of Passive and Active Targeting in the Era of Modern Cancer Biology. Adv Drug Deliv Rev (2014) 66:2-25. doi: 10.1016/j.addr.2013.11.009

292. De Filippo K, Dudeck A, Hasenberg M, Nye E, van Rooijen N, Hartmann K, et al. Mast Cell and Macrophage Chemokines CXCL1/CXCL2 Control the Early Stage of Neutrophil Recruitment During Tissue Inflammation. Blood (2013) 121:4930-7. doi: 10.1182/blood-2013-02-486217

293. Keshari RS, Jyoti A, Dubey M, Kothari N, Kohli M, Bogra J, et al. Cytokines Induced Neutrophil Extracellular Traps Formation: Implication for the Inflammatory Disease Condition. PloS One (2012) 7:e48111. doi: 10.1371/ journal.pone.0048111

294. Schneider JR, Kwan BS, MD K, Boockvar J.A., MD. Neutrophil-Guided Drug Delivery for Targeting Residual Glioma Cells. Neurosurgery (2018) 82(1): N7-9. doi: 10.1093/neuros/nyx531

295. Wu M, Zhang H, Tie C, Yan C, Deng Z, Wan Q, et al. MR Imaging Tracking of Inflammation-Activatable Engineered Neutrophils for Targeted Therapy of Surgically Treated Glioma. Nat Commun (2018) 9:4777. doi: 10.1038/ s41467-018-07250-6

296. Willis VC, Banda NK, Cordova KN, Chandra PE, Robinson WH, Cooper DC, et al. Protein Arginine Deiminase 4 Inhibition Is Sufficient for the Amelioration of Collagen-Induced Arthritis. Clin Exp Immunol (2017) 188:263-74. doi: 10.1111/cei.12932 
297. Chu D, Gao J, Wang Z. Neutrophil-Mediated Delivery of Therapeutic Nanoparticles Across Blood Vessel Barrier for Treatment of Inflammation and Infection. ACS Nano (2015) 9:11800-11. doi: 10.1021/acsnano.5b05583

Conflict of Interest: The authors declare that the research was conducted in the absence of any commercial or financial relationships that could be construed as a potential conflict of interest.

Publisher's Note: All claims expressed in this article are solely those of the authors and do not necessarily represent those of their affiliated organizations, or those of the publisher, the editors and the reviewers. Any product that may be evaluated in this article, or claim that may be made by its manufacturer, is not guaranteed or endorsed by the publisher.

Copyright (c) $2021 \mathrm{Lin}$, Wei, Chen, Lim and Hwang. This is an open-access article distributed under the terms of the Creative Commons Attribution License (CC BY). The use, distribution or reproduction in other forums is permitted, provided the original author(s) and the copyright owner(s) are credited and that the original publication in this journal is cited, in accordance with accepted academic practice. No use, distribution or reproduction is permitted which does not comply with these terms. 